\section{Final 2015 Reports of Nationally Notifiable Infectious Diseases and Conditions}

The table listed in this report on pages 1307-1321 presents finalized data, as of June 30, 2016, from the National Notifiable Diseases Surveillance System (NNDSS) for 2015. These data will be published in more detail in the Summary of Notifiable Infectious Diseases and Conditions - United States, 2015 (1). Because no cases were reported in the United States during 2015, the following diseases do not appear in this early release table: anthrax; dengue hemorrhagic fever; diphtheria; eastern equine encephalitis virus disease, nonneuroinvasive; poliomyelitis, paralytic; poliovirus infection, nonparalytic; severe acute respiratory syndrome-associated coronavirus disease (SARS-CoV); smallpox; western equine encephalitis virus disease, neuroinvasive and nonneuroinvasive; yellow fever; and viral hemorrhagic fevers.

Policies for reporting NNDSS data to CDC can vary by disease or reporting jurisdiction. The publication criteria used for the 2015 finalized tables are listed in the "Print Criteria" column of the NNDSS event code list (https://wwwn.cdc.gov/ nndss/document/National_Notifiable_Diseases_Surveillance_ System_Event_Code_List_2015_v7.xlsx).
In addition, only cases from jurisdictions where the nationally notifiable disease was reportable in 2015 are published. The NNDSS website (https://wwwn.cdc.gov/nndss/) is updated annually to include the latest national surveillance case definitions approved by the Council of State and Territorial Epidemiologists (CSTE) for classifying and enumerating cases of nationally notifiable infectious diseases.

Population estimates are from the National Center for Health Statistics postcensal estimates of the resident population of the United States for July 1, 2014-July 1, 2015, by year, county, single-year of age ( 0 to $\geq 85$ years), bridged race (white, black or African American, American Indian or Alaska Native, Asian, or Pacific Islander), Hispanic origin (not Hispanic or Latino, Hispanic or Latino), and sex (vintage 2015), prepared under a collaborative arrangement with the U.S. Census Bureau. Population estimates released for states as of June 28, 2016 are available at http://www.cdc.gov/nchs/nvss/bridged_race/data_ documentation.htm\#vintage2015. Population estimates for territories are 2015 estimates from the U.S. Census Bureau (2).

\section{References}

1. CDC. Summary of notifiable infectious diseases and conditions-United States, 2015. MMWR Morb Mortal Wkly Rep. In press 2017.

2. US Census Bureau. International data base. Washington, DC: US Census Bureau; 2015. http://www.census.gov/population/international/data/idb/ informationGateway.php 
TABLE 2a. Reported cases of notifiable diseases, ${ }^{*}$ by geographic division and area - United States and U.S. territories, 2015

\begin{tabular}{|c|c|c|c|c|c|c|c|c|}
\hline \multirow[b]{3}{*}{ Area } & \multirow{3}{*}{$\begin{array}{c}\text { Total resident } \\
\text { population } \\
\text { (in thousands) }\end{array}$} & \multicolumn{7}{|c|}{ Arboviral diseases $^{\dagger}$} \\
\hline & & \multicolumn{2}{|c|}{ Chikungunya virus disease } & \multirow{2}{*}{$\begin{array}{c}\begin{array}{c}\text { Eastern equine } \\
\text { encephalitis } \\
\text { virus disease }\end{array} \\
\begin{array}{c}\text { Neuro- } \\
\text { invasive }\end{array} \\
\end{array}$} & \multicolumn{2}{|c|}{ Jamestown Canyon virus disease } & \multicolumn{2}{|c|}{ LaCrosse virus disease } \\
\hline & & $\begin{array}{c}\text { Neuro- } \\
\text { invasive }\end{array}$ & $\begin{array}{c}\text { Nonneuro- } \\
\text { invasive }\end{array}$ & & $\begin{array}{c}\text { Neuro- } \\
\text { invasive }\end{array}$ & $\begin{array}{c}\text { Nonneuro- } \\
\text { invasive }\end{array}$ & $\begin{array}{c}\text { Neuro- } \\
\text { invasive }\end{array}$ & $\begin{array}{c}\text { Nonneuro- } \\
\text { invasive }\end{array}$ \\
\hline United States & 321,417 & 4 & 892 & 6 & 6 & 5 & 51 & 4 \\
\hline $\begin{array}{l}\text { New England } \\
\text { Connecticut }\end{array}$ & $\begin{array}{r}14,727 \\
3,591\end{array}$ & - & $\begin{array}{l}59 \\
16\end{array}$ & 1 & 1 & - & - & - \\
\hline Maine & 1,329 & - & 2 & 1 & - & - & - & - \\
\hline Massachusetts & 6,794 & - & 34 & - & 1 & - & - & - \\
\hline New Hampshire & 1,331 & - & 1 & - & - & - & - & - \\
\hline Rhode Island & 1,056 & - & 5 & - & - & - & - & - \\
\hline Vermont & 626 & - & 1 & - & - & - & - & - \\
\hline Mid. Atlantic & 41,556 & - & 138 & 3 & 1 & - & - & - \\
\hline New Jersey & 8,958 & - & 31 & - & 1 & - & - & - \\
\hline New York (Upstate) & 11,245 & - & 37 & 3 & - & - & - & - \\
\hline New York City & 8,550 & - & 62 & - & - & - & - & - \\
\hline Pennsylvania & 12,803 & - & 8 & - & - & - & - & - \\
\hline E. N. Central & 46,787 & 1 & 53 & - & 3 & 2 & 29 & 1 \\
\hline $\begin{array}{l}\text { Illinois } \\
\text { Indiana }\end{array}$ & $\begin{array}{r}12,860 \\
6620\end{array}$ & 1 & $\begin{array}{r}19 \\
7\end{array}$ & $=$ & $\bar{z}$ & $\bar{z}$ & $\bar{z}$ & - \\
\hline Michigan & $\begin{array}{l}6,620 \\
9,923\end{array}$ & - & 9 & - & - & - & - & - \\
\hline Ohio & 11,613 & - & 10 & - & 1 & - & 23 & 1 \\
\hline Wisconsin & 5,771 & - & 8 & - & 2 & 2 & 6 & - \\
\hline W.N. Central & 21,121 & 1 & 40 & - & 1 & 2 & 1 & 1 \\
\hline lowa & 3,124 & - & 4 & - & - & 1 & - & - \\
\hline Kansas & 2,912 & - & 11 & - & - & - & 1 & - \\
\hline Minnesota & 5,490 & - & 15 & - & 1 & 1 & - & 1 \\
\hline Missouri & 6,084 & - & 5 & - & - & - & - & - \\
\hline Nebraska & 1,896 & - & 4 & - & - & - & - & - \\
\hline North Dakota & 757 & 1 & 1 & - & - & - & - & - \\
\hline South Dakota & 858 & - & - & - & - & - & - & - \\
\hline S. Atlantic & 63,276 & 1 & 146 & 1 & - & - & 17 & 1 \\
\hline Delaware & 946 & - & - & - & - & - & - & - \\
\hline District of Columbia & 672 & - & - & - & - & - & - & - \\
\hline Florida & 20,271 & - & 73 & - & - & - & - & - \\
\hline Georgia & 10,215 & - & 9 & - & - & - & 2 & - \\
\hline Maryland & 6,006 & - & 19 & - & - & - & - & - \\
\hline North Carolina & 10,043 & - & 19 & 1 & - & - & 11 & - \\
\hline South Carolina & 4,896 & 1 & 2 & - & - & - & 1 & - \\
\hline Virginia & 8,383 & - & 24 & - & - & - & - & - \\
\hline West Virginia & 1,844 & - & - & - & - & - & 3 & 1 \\
\hline E.S. Central & 18,876 & - & 19 & - & - & - & 3 & 1 \\
\hline Alabama & 4,859 & - & 1 & - & - & - & - & - \\
\hline Kentucky & 4,425 & - & 8 & - & - & - & - & - \\
\hline Mississippi & 2,992 & - & 1 & - & - & - & - & - \\
\hline Tennessee & 6,600 & - & 9 & - & - & - & 3 & 1 \\
\hline W.S. Central & 39,029 & - & 70 & 1 & - & - & 1 & - \\
\hline Arkansas & 2,978 & - & 4 & - & - & - & - & - \\
\hline Louisiana & 4,671 & - & 7 & 1 & - & - & 1 & - \\
\hline Oklahoma & 3,911 & - & 4 & - & - & - & - & - \\
\hline Texas & 27,469 & - & 55 & - & - & - & - & - \\
\hline Mountain & 23,531 & - & 42 & - & - & 1 & - & - \\
\hline Arizona & 6,828 & - & 24 & - & - & - & - & - \\
\hline Colorado & 5,457 & - & 8 & - & - & - & - & - \\
\hline Idaho & 1,655 & - & 5 & - & - & - & - & - \\
\hline Montana & 1,033 & - & 1 & - & - & - & - & - \\
\hline Nevada & 2,891 & - & 1 & - & - & - & - & - \\
\hline New Mexico & 2,085 & - & - & - & - & - & - & - \\
\hline Utah & 2,996 & - & 3 & - & - & - & - & - \\
\hline Wyoming & 586 & - & - & - & - & 1 & - & - \\
\hline Pacific & 52,514 & 1 & 325 & - & - & - & - & - \\
\hline Alaska & 738 & - & 1 & - & - & - & - & - \\
\hline California & 39,145 & - & 276 & - & - & - & - & - \\
\hline Hawaii & 1,432 & - & 7 & - & - & - & - & - \\
\hline Oregon & 4,029 & - & 3 & - & - & - & - & - \\
\hline Washington & 7,170 & 1 & 38 & - & - & - & - & - \\
\hline Territories & & & & & & & & \\
\hline American Samoa & 54 & - & - & - & - & - & - & - \\
\hline C.N.M.I. & 52 & - & - & - & - & - & - & - \\
\hline Guam & 162 & - & - & - & - & - & - & - \\
\hline Puerto Rico & 3,598 & - & 216 & - & - & - & - & - \\
\hline U.S. Virgin Islands & 104 & - & 21 & - & - & - & - & - \\
\hline
\end{tabular}

N: Not Reportable U: Unavailable —: No reported cases C.N.M.I.: Commonwealth of Northern Mariana Islands

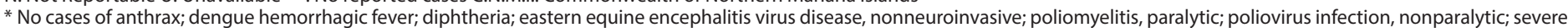

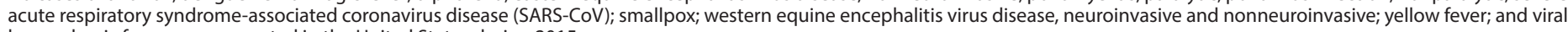
hemorrhagic fevers were reported in the United States during 2015.

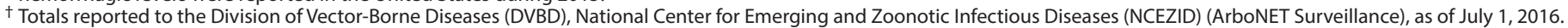


TABLE 2b. Reported cases of notifiable diseases, ${ }^{*}$ by geographic division and area - United States and U.S. territories, 2015

\begin{tabular}{|c|c|c|c|c|c|c|}
\hline \multirow[b]{3}{*}{ Area } & \multicolumn{6}{|c|}{ Arboviral diseases (continued) ${ }^{\dagger}$} \\
\hline & \multicolumn{2}{|c|}{ Powassan virus disease } & \multicolumn{2}{|c|}{ St. Louis encephalitis virus disease } & \multicolumn{2}{|c|}{ West Nile virus disease } \\
\hline & Neuroinvasive & Nonneuroinvasive & Neuroinvasive & Nonneuroinvasive & Neuroinvasive & Nonneuroinvasive \\
\hline United States & 6 & 1 & 19 & 4 & 1,455 & 720 \\
\hline $\begin{array}{l}\text { New England } \\
\text { Connecticut }\end{array}$ & 4 & - & - & - & $\begin{array}{r}16 \\
8\end{array}$ & $\begin{array}{l}5 \\
2\end{array}$ \\
\hline Maine & $\overline{1}$ & - & - & - & 1 & 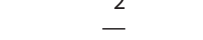 \\
\hline Massachusetts & 3 & - & - & - & 7 & 3 \\
\hline New Hampshire & - & - & - & - & - & - \\
\hline Rhode Island & - & - & - & - & - & - \\
\hline Vermont & - & - & - & - & - & - \\
\hline Mid. Atlantic & 1 & 1 & - & - & 82 & 31 \\
\hline New Jersey & 1 & - & - & - & 23 & 3 \\
\hline New York (Upstate) & - & 1 & - & - & 12 & 7 \\
\hline New York City & - & - & - & - & 30 & 8 \\
\hline Pennsylvania & - & - & - & - & 17 & 13 \\
\hline E. N. Central & 1 & - & - & - & 112 & 48 \\
\hline Illinois & - & - & - & - & 51 & 26 \\
\hline Indiana & - & - & - & - & 16 & 5 \\
\hline Michigan & - & - & - & - & 16 & 2 \\
\hline Ohio & - & - & - & - & 23 & 12 \\
\hline Wisconsin & 1 & - & - & - & 6 & 3 \\
\hline W.N. Central & - & - & - & - & 82 & 135 \\
\hline lowa & - & - & - & - & 4 & 10 \\
\hline Kansas & - & - & - & - & 12 & 22 \\
\hline Minnesota & - & - & - & - & 3 & 6 \\
\hline Missouri & - & - & - & - & 23 & 6 \\
\hline Nebraska & - & - & - & - & 19 & 49 \\
\hline North Dakota & - & - & - & - & 10 & 13 \\
\hline South Dakota & - & - & - & - & 11 & 29 \\
\hline S. Atlantic & - & - & - & - & 76 & 33 \\
\hline Delaware & - & - & - & - & - & 6 \\
\hline District of Columbia & - & - & - & - & 3 & 2 \\
\hline Florida & - & - & - & - & 12 & 1 \\
\hline Georgia & - & - & - & - & 13 & 2 \\
\hline Maryland & - & - & - & - & 31 & 14 \\
\hline North Carolina & - & - & - & - & 4 & - \\
\hline South Carolina & - & - & - & - & - & - \\
\hline Virginia & - & - & - & - & 13 & 8 \\
\hline West Virginia & - & - & - & - & - & - \\
\hline E.S. Central & - & - & - & - & 36 & 21 \\
\hline Alabama & - & - & - & - & 5 & 4 \\
\hline Kentucky & - & - & - & - & 1 & 1 \\
\hline Mississippi & - & - & - & - & 25 & 13 \\
\hline Tennessee & - & - & - & - & 5 & 3 \\
\hline W.S. Central & - & - & - & - & 302 & 131 \\
\hline Arkansas & - & - & - & - & 16 & 2 \\
\hline Louisiana & - & - & - & - & 41 & 10 \\
\hline Oklahoma & - & - & - & - & 49 & 40 \\
\hline Texas & - & - & - & - & 196 & 79 \\
\hline Mountain & - & - & 19 & 4 & 156 & 101 \\
\hline Arizona & - & - & 19 & 4 & 67 & 36 \\
\hline Colorado & - & - & - & - & 57 & 44 \\
\hline Idaho & - & - & - & - & 5 & 8 \\
\hline Montana & - & - & - & - & 3 & - \\
\hline Nevada & - & - & - & - & 4 & 3 \\
\hline New Mexico & - & - & - & - & 12 & 2 \\
\hline Utah & - & - & - & - & 5 & 3 \\
\hline Wyoming & - & - & - & - & 3 & 5 \\
\hline Pacific & - & - & - & - & 593 & 215 \\
\hline Alaska & - & - & - & - & - & - \\
\hline California & - & - & - & - & 585 & 198 \\
\hline Hawaii & - & - & - & - & - & - \\
\hline Oregon & - & - & - & - & - & 1 \\
\hline Washington & - & - & - & - & 8 & 16 \\
\hline Territories & & & & & & \\
\hline American Samoa & - & - & - & - & - & - \\
\hline C.N.M.I. & - & - & - & - & - & - \\
\hline Guam & - & - & - & - & - & - \\
\hline Puerto Rico & - & - & - & - & - & - \\
\hline U.S. Virgin Islands & - & - & - & - & - & - \\
\hline
\end{tabular}

N: Not Reportable U: Unavailable -: No reported cases C.N.M.I.: Commonwealth of Northern Mariana Islands

* No cases of anthrax; dengue hemorrhagic fever; diphtheria; eastern equine encephalitis virus disease, nonneuroinvasive; poliomyelitis, paralytic; poliovirus infection, nonparalytic; severe

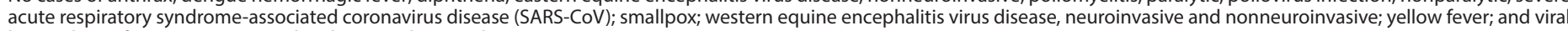
hemorrhagic fevers were reported in the United States during 2015.

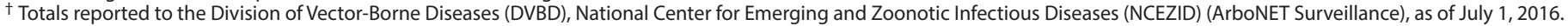


Morbidity and Mortality Weekly Report

TABLE 2c. Reported cases of notifiable diseases, ${ }^{*}$ by geographic division and area - United States and U.S. territories, 2015

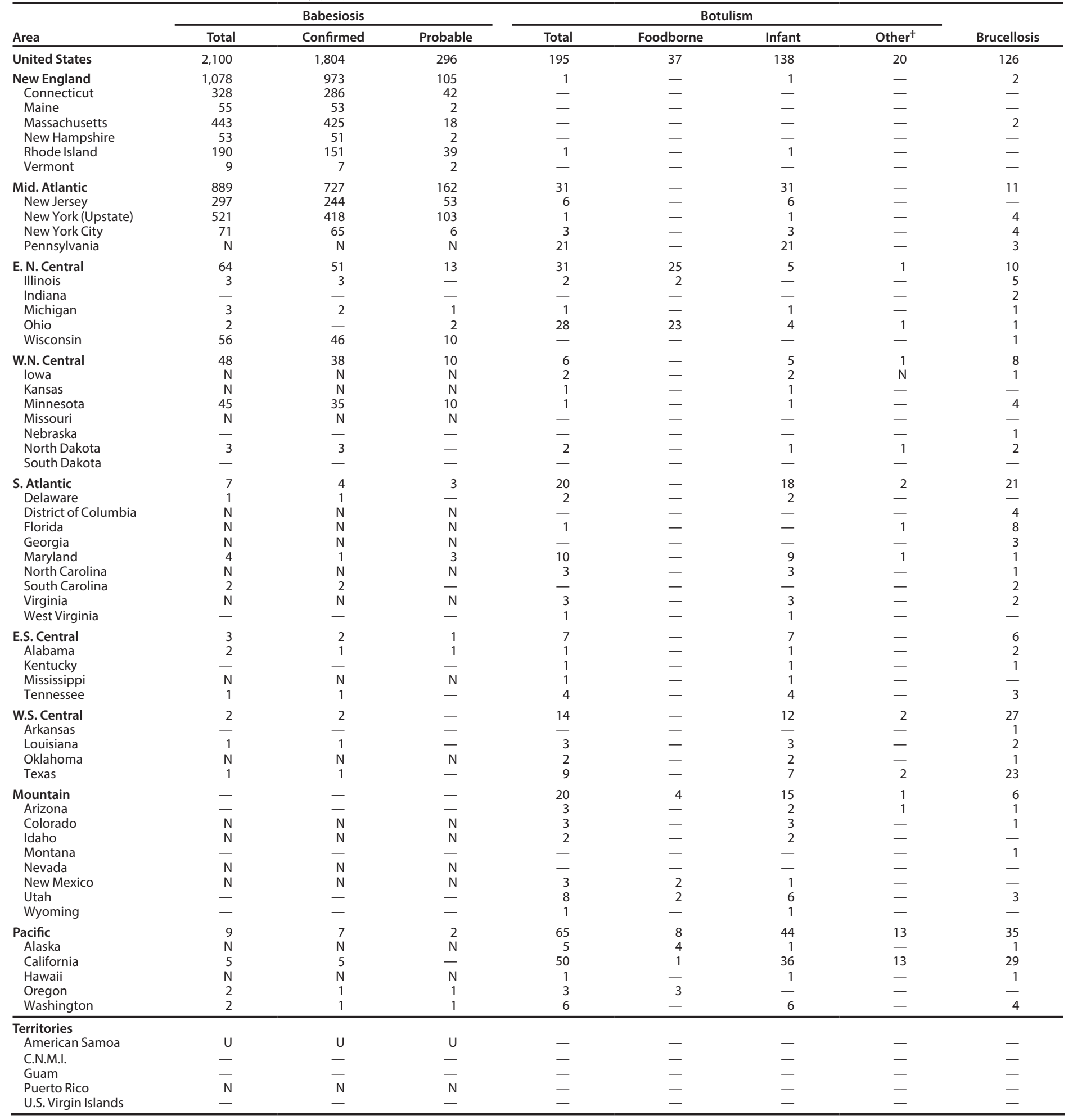

N: Not Reportable U: Unavailable - : No reported cases C.N.M.I.: Commonwealth of Northern Mariana Islands

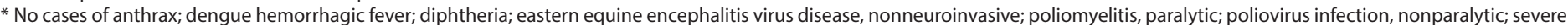

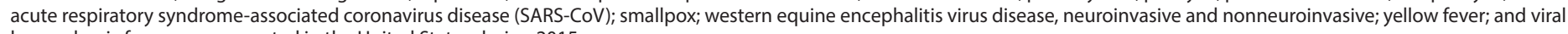
hemorrhagic fevers were reported in the United States during 2015.

$\dagger$ Includes cases reported as wound and unspecified botulism. 
Morbidity and Mortality Weekly Report

TABLE 2d. Reported cases of notifiable diseases, ${ }^{*}$ by geographic division and area — United States and U.S. territories, 2015

\begin{tabular}{|c|c|c|c|c|c|}
\hline Area & Campylobacteriosis & Chancroid $^{+}$ & $\begin{array}{c}\text { Chlamydia trachomatis } \\
\text { infection }^{\dagger}\end{array}$ & Cholera & Coccidioidomycosis $^{\S}$ \\
\hline United States & 54,556 & 11 & $1,526,658$ & 8 & 11,072 \\
\hline $\begin{array}{l}\text { New England } \\
\text { Connecticut } \\
\text { Maine } \\
\text { Massachusetts } \\
\text { New Hampshire } \\
\text { Rhode Island } \\
\text { Vermont }\end{array}$ & $\begin{array}{r}3,114 \\
780 \\
221 \\
1,456 \\
252 \\
232 \\
173\end{array}$ & $\begin{array}{l}\frac{3}{-} \\
-3 \\
- \\
-\end{array}$ & $\begin{array}{r}50,762 \\
13,126 \\
3,965 \\
24,100 \\
3,095 \\
4,575 \\
1,901\end{array}$ & $\begin{array}{l}\overline{-} \\
\overline{-} \\
\overline{-} \\
\overline{-}\end{array}$ & $\begin{array}{l}\bar{N} \\
\mathrm{~N} \\
\overline{-} \\
\bar{N}\end{array}$ \\
\hline $\begin{array}{l}\text { Mid. Atlantic } \\
\text { New Jersey } \\
\text { New York (Upstate) } \\
\text { New York City } \\
\text { Pennsylvania }\end{array}$ & $\begin{array}{l}8,005 \\
1,907 \\
1,982 \\
1,716 \\
2,400\end{array}$ & $\begin{array}{l}\overline{-} \\
\bar{z} \\
\overline{-}\end{array}$ & $\begin{array}{r}188,412 \\
31,337 \\
40,860 \\
62,755 \\
53,460\end{array}$ & $\begin{array}{l}\frac{2}{2} \\
- \\
-\end{array}$ & $\begin{array}{l}-\bar{N} \\
N \\
N \\
N\end{array}$ \\
\hline $\begin{array}{l}\text { E. N. Central } \\
\text { Illinois } \\
\text { Indiana } \\
\text { Michigan } \\
\text { Ohio } \\
\text { Wisconsin }\end{array}$ & $\begin{array}{r}5,433 \\
\mathrm{~N} \\
914 \\
1,339 \\
1,722 \\
1,458\end{array}$ & $\begin{array}{l}\frac{1}{1} \\
- \\
-\end{array}$ & $\begin{array}{r}226,089 \\
69,610 \\
28,886 \\
46,486 \\
56,726 \\
24,381\end{array}$ & $\begin{array}{l}- \\
\overline{-} \\
\overline{-} \\
-\end{array}$ & $\begin{array}{r}40 \\
N \\
N \\
20 \\
13 \\
7\end{array}$ \\
\hline $\begin{array}{l}\text { W.N. Central } \\
\text { lowa } \\
\text { Kansas } \\
\text { Minnesota } \\
\text { Missouri } \\
\text { Nebraska } \\
\text { North Dakota } \\
\text { South Dakota }\end{array}$ & $\begin{array}{r}5,092 \\
769 \\
679 \\
1,407 \\
1,207 \\
505 \\
176 \\
349\end{array}$ & $\begin{array}{l}- \\
= \\
= \\
= \\
=\end{array}$ & $\begin{array}{r}88,804 \\
12,085 \\
11,464 \\
21,243 \\
28,948 \\
7,956 \\
3,159 \\
3,949\end{array}$ & $\begin{array}{l}= \\
= \\
= \\
= \\
=\end{array}$ & $\begin{array}{r}108 \\
\mathrm{~N} \\
\mathrm{~N} \\
80 \\
10 \\
9 \\
9 \\
\mathrm{~N}\end{array}$ \\
\hline $\begin{array}{l}\text { S. Atlantic } \\
\text { Delaware } \\
\text { District of Columbia } \\
\text { Florida } \\
\text { Georgia } \\
\text { Maryland } \\
\text { North Carolina } \\
\text { South Carolina } \\
\text { Virginia } \\
\text { West Virginia }\end{array}$ & $\begin{array}{r}8,949 \\
156 \\
8 \\
8,351 \\
1,093 \\
789 \\
1,298 \\
363 \\
1,564 \\
327\end{array}$ & $\begin{array}{l}- \\
\overline{-} \\
= \\
= \\
= \\
=\end{array}$ & $\begin{array}{r}320,277 \\
4,605 \\
7,894 \\
90,468 \\
57,639 \\
27,450 \\
64,376 \\
27,538 \\
35,349 \\
4,958\end{array}$ & $\begin{array}{l}\frac{3}{-} \\
\overline{3} \\
- \\
- \\
- \\
- \\
-\end{array}$ & $\begin{array}{l}\frac{5}{1} \\
N \\
N \\
N \\
5 \\
N \\
N \\
N \\
N\end{array}$ \\
\hline $\begin{array}{l}\text { E.S. Central } \\
\text { Alabama } \\
\text { Kentucky } \\
\text { Mississippi } \\
\text { Tennessee }\end{array}$ & $\begin{array}{r}2,331 \\
589 \\
788 \\
195 \\
759\end{array}$ & $\begin{array}{l}\overline{-} \\
\overline{-} \\
\overline{-}\end{array}$ & $\begin{array}{l}92,446 \\
26,359 \\
17,444 \\
17,371 \\
31,272\end{array}$ & $\begin{array}{l}1 \\
1 \\
- \\
-\end{array}$ & $\begin{array}{l}\bar{N} \\
\bar{N} \\
N\end{array}$ \\
\hline $\begin{array}{l}\text { W.S. Central } \\
\text { Arkansas } \\
\text { Louisiana } \\
\text { Oklahoma } \\
\text { Texas }\end{array}$ & $\begin{array}{r}5,619 \\
448 \\
365 \\
862 \\
3,944\end{array}$ & $\begin{array}{l}\frac{2}{-} \\
\frac{2}{2}\end{array}$ & $\begin{array}{r}210,674 \\
16,166 \\
32,325 \\
21,025 \\
141,158\end{array}$ & $\begin{array}{l}- \\
\overline{-} \\
\overline{-}\end{array}$ & $\begin{array}{r}11 \\
7 \\
4 \\
\mathrm{~N} \\
\mathrm{~N}\end{array}$ \\
\hline $\begin{array}{l}\text { Mountain } \\
\text { Arizona } \\
\text { Colorado } \\
\text { Idaho } \\
\text { Montana } \\
\text { Nevada } \\
\text { New Mexico } \\
\text { Utah } \\
\text { Wyoming }\end{array}$ & $\begin{array}{r}4,319 \\
1,379 \\
965 \\
409 \\
323 \\
175 \\
479 \\
435 \\
154\end{array}$ & $\begin{array}{l}2 \\
1 \\
= \\
= \\
= \\
= \\
-1\end{array}$ & $\begin{array}{r}102,286 \\
32,387 \\
23,857 \\
5,631 \\
4,184 \\
12,925 \\
12,632 \\
8,633 \\
2,037\end{array}$ & $\begin{array}{l}1 \\
- \\
- \\
- \\
- \\
-\end{array}$ & $\begin{array}{r}7,845 \\
7,622 \\
\mathrm{~N} \\
\mathrm{~N} \\
12 \\
115 \\
31 \\
52 \\
13\end{array}$ \\
\hline $\begin{array}{l}\text { Pacific } \\
\text { Alaska } \\
\text { California } \\
\text { Hawaii } \\
\text { Oregon } \\
\text { Washington }\end{array}$ & $\begin{array}{r}11,694 \\
98 \\
8,304 \\
569 \\
882 \\
1,841\end{array}$ & $\begin{array}{l}\frac{3}{2} \\
\frac{-}{1}\end{array}$ & $\begin{array}{r}246,908 \\
5,660 \\
189,170 \\
7,074 \\
16,305 \\
28,699 \\
\end{array}$ & $\begin{array}{l}1 \\
- \\
- \\
-\end{array}$ & $\begin{array}{r}3,063 \\
\mathrm{~N} \\
3,053 \\
\mathrm{~N} \\
10 \\
\mathrm{~N}\end{array}$ \\
\hline $\begin{array}{l}\text { Territories } \\
\text { American Samoa } \\
\text { C.N.M.I. } \\
\text { Guam } \\
\text { Puerto Rico } \\
\text { U.S. Virgin Island }\end{array}$ & $\begin{array}{l}- \\
\overline{4} \\
28 \\
-\end{array}$ & $\begin{array}{l}\overline{-} \\
\overline{-} \\
\overline{-}\end{array}$ & $\begin{array}{r}- \\
881 \\
5,295 \\
743\end{array}$ & $\begin{array}{l}\overline{-} \\
\overline{-} \\
\overline{-}\end{array}$ & $\begin{array}{l}\mathrm{N} \\
- \\
- \\
-\end{array}$ \\
\hline
\end{tabular}

N: Not Reportable U: Unavailable —: No reported cases C.N.M.I.: Commonwealth of Northern Mariana Islands

* No cases of anthrax; dengue hemorrhagic fever; diphtheria; eastern equine encephalitis virus disease, nonneuroinvasive; poliomyelitis, paralytic; poliovirus infection, nonparalytic; severe acute respiratory syndrome-associated coronavirus disease (SARS-CoV); smallpox; western equine encephalitis virus disease, neuroinvasive and nonneuroinvasive; yellow fever; and viral hemorrhagic fevers were reported in the United States during 2015.

† Totals reported to the Division of STD Prevention (DSTDP), National Center for HIV/AIDS, Viral Hepatitis, STD, and TB Prevention (NCHHSTP), as of June 8, 2016.

$\S$ Notifiable in $<25$ states. 
TABLE 2e. Reported cases of notifiable diseases, ${ }^{*}$ by geographic division and area — United States and U.S. territories, 2015

\begin{tabular}{|c|c|c|c|c|c|c|c|}
\hline \multirow[b]{2}{*}{ Area } & \multicolumn{3}{|c|}{ Cryptosporidiosis } & \multirow[b]{2}{*}{ Cyclosporiasis } & \multicolumn{3}{|c|}{ Dengue virus infections $^{\dagger}$} \\
\hline & Total & Confirmed & Probable & & Dengue & Dengue-like illness & Severe Dengue \\
\hline United States & 9,735 & 6,145 & 3,590 & 645 & 929 & 16 & 6 \\
\hline $\begin{array}{l}\text { New England } \\
\text { Connecticut } \\
\text { Maine } \\
\text { Massachusetts } \\
\text { New Hampshire } \\
\text { Rhode Island } \\
\text { Vermont }\end{array}$ & $\begin{array}{r}443 \\
82 \\
34 \\
211 \\
36 \\
25 \\
55\end{array}$ & $\begin{array}{r}394 \\
82 \\
24 \\
211 \\
23 \\
25 \\
29\end{array}$ & $\begin{array}{l}\frac{49}{10} \\
\frac{13}{26}\end{array}$ & $\begin{array}{r}40 \\
16 \\
\mathrm{~N} \\
21 \\
3 \\
- \\
-\end{array}$ & $\begin{array}{r}22 \\
4 \\
4 \\
8 \\
1 \\
3 \\
2\end{array}$ & $\begin{array}{r}2 \\
1 \\
- \\
- \\
- \\
-\end{array}$ & $\begin{array}{l}- \\
- \\
- \\
-\end{array}$ \\
\hline $\begin{array}{l}\text { Mid. Atlantic } \\
\text { New Jersey } \\
\text { New York (Upstate) } \\
\text { New York City } \\
\text { Pennsylvania }\end{array}$ & $\begin{array}{r}818 \\
86 \\
269 \\
133 \\
330\end{array}$ & $\begin{array}{r}673 \\
84 \\
263 \\
131 \\
195\end{array}$ & $\begin{array}{r}145 \\
2 \\
6 \\
2 \\
135\end{array}$ & $\begin{array}{r}93 \\
21 \\
21 \\
51 \\
\mathrm{~N}\end{array}$ & $\begin{array}{r}187 \\
57 \\
33 \\
74 \\
23\end{array}$ & $\begin{array}{r}4 \\
3 \\
-1 \\
-\end{array}$ & $\begin{array}{l}\frac{1}{-} \\
-1 \\
-\end{array}$ \\
\hline $\begin{array}{l}\text { E. N. Central } \\
\text { Illinois } \\
\text { Indiana } \\
\text { Michigan } \\
\text { Ohio } \\
\text { Wisconsin }\end{array}$ & $\begin{array}{r}1,672 \\
240 \\
188 \\
238 \\
424 \\
582\end{array}$ & $\begin{array}{r}1,182 \\
100 \\
123 \\
210 \\
167 \\
582\end{array}$ & $\begin{array}{r}490 \\
140 \\
65 \\
28 \\
257 \\
-\end{array}$ & $\begin{array}{r}45 \\
21 \\
- \\
8 \\
2 \\
14\end{array}$ & $\begin{array}{r}63 \\
29 \\
- \\
16 \\
11 \\
7\end{array}$ & $\begin{array}{l}- \\
- \\
- \\
-\end{array}$ & $\begin{array}{l}- \\
- \\
- \\
-\end{array}$ \\
\hline $\begin{array}{l}\text { W.N. Central } \\
\text { lowa } \\
\text { Kansas } \\
\text { Minnesota } \\
\text { Missouri } \\
\text { Nebraska } \\
\text { North Dakota } \\
\text { South Dakota }\end{array}$ & $\begin{array}{r}1,794 \\
373 \\
179 \\
318 \\
401 \\
259 \\
17 \\
247\end{array}$ & $\begin{array}{r}826 \\
109 \\
94 \\
232 \\
160 \\
200 \\
17 \\
14\end{array}$ & $\begin{array}{r}968 \\
264 \\
85 \\
86 \\
241 \\
59 \\
- \\
233\end{array}$ & $\begin{array}{r}20 \\
4 \\
6 \\
1 \\
5 \\
4 \\
\mathrm{~N} \\
-\end{array}$ & $\begin{array}{r}36 \\
4 \\
4 \\
20 \\
3 \\
2 \\
1 \\
2\end{array}$ & $\begin{array}{l}- \\
- \\
- \\
- \\
-\end{array}$ & $\begin{array}{l}1 \\
- \\
-1 \\
- \\
-\end{array}$ \\
\hline $\begin{array}{l}\text { S. Atlantic } \\
\text { Delaware } \\
\text { District of Columbia } \\
\text { Florida } \\
\text { Georgia } \\
\text { Maryland } \\
\text { North Carolina } \\
\text { South Carolina } \\
\text { Virginia } \\
\text { West Virginia }\end{array}$ & $\begin{array}{r}1,960 \\
15 \\
24 \\
856 \\
350 \\
99 \\
282 \\
77 \\
234 \\
23\end{array}$ & $\begin{array}{r}1,169 \\
10 \\
21 \\
384 \\
350 \\
73 \\
192 \\
50 \\
72 \\
17\end{array}$ & $\begin{array}{r}791 \\
5 \\
3 \\
472 \\
- \\
26 \\
90 \\
27 \\
162 \\
6\end{array}$ & $\begin{array}{r}84 \\
1 \\
-32 \\
34 \\
3 \\
4 \\
2 \\
8 \\
-\end{array}$ & $\begin{array}{r}148 \\
1 \\
8 \\
82 \\
8 \\
11 \\
9 \\
4 \\
24 \\
1\end{array}$ & $\begin{array}{l}\frac{3}{2} \\
- \\
-1 \\
- \\
- \\
-\end{array}$ & $\begin{array}{l}\frac{2}{1} \\
- \\
-1 \\
- \\
- \\
-\end{array}$ \\
\hline $\begin{array}{l}\text { E.S. Central } \\
\text { Alabama } \\
\text { Kentucky } \\
\text { Mississippi } \\
\text { Tennessee }\end{array}$ & $\begin{array}{r}669 \\
261 \\
95 \\
35 \\
278\end{array}$ & $\begin{array}{r}439 \\
147 \\
52 \\
34 \\
206\end{array}$ & $\begin{array}{r}230 \\
114 \\
43 \\
1 \\
72\end{array}$ & $\begin{array}{c}1 \\
\mathrm{~N} \\
\mathrm{~N} \\
1\end{array}$ & $\begin{array}{r}19 \\
3 \\
1 \\
2 \\
13\end{array}$ & $\begin{array}{l}- \\
- \\
-\end{array}$ & $\begin{array}{l}- \\
- \\
-\end{array}$ \\
\hline $\begin{array}{l}\text { W.S. Central } \\
\text { Arkansas } \\
\text { Louisiana } \\
\text { Oklahoma } \\
\text { Texas }\end{array}$ & $\begin{array}{r}1,057 \\
69 \\
132 \\
116 \\
740\end{array}$ & $\begin{array}{r}648 \\
65 \\
66 \\
48 \\
469\end{array}$ & $\begin{array}{r}409 \\
4 \\
66 \\
68 \\
271\end{array}$ & $\begin{array}{r}320 \\
3 \\
1 \\
N \\
316\end{array}$ & $\begin{array}{r}37 \\
1 \\
4 \\
2 \\
30\end{array}$ & $\begin{array}{l}- \\
- \\
-\end{array}$ & $\frac{2}{-}$ \\
\hline $\begin{array}{l}\text { Mountain } \\
\text { Arizona } \\
\text { Colorado } \\
\text { Idaho } \\
\text { Montana } \\
\text { Nevada } \\
\text { New Mexico } \\
\text { Utah } \\
\text { Wyoming }\end{array}$ & $\begin{array}{r}596 \\
62 \\
136 \\
95 \\
39 \\
12 \\
51 \\
173 \\
28\end{array}$ & $\begin{array}{r}358 \\
49 \\
77 \\
85 \\
39 \\
8 \\
48 \\
24 \\
28\end{array}$ & $\begin{array}{r}238 \\
13 \\
59 \\
10 \\
- \\
4 \\
3 \\
149 \\
-\end{array}$ & $\begin{array}{r}22 \\
1 \\
8 \\
\mathrm{~N} \\
3 \\
\mathrm{~N} \\
2 \\
8 \\
-\end{array}$ & $\begin{array}{r}37 \\
12 \\
13 \\
3 \\
4 \\
1 \\
3 \\
1 \\
-\end{array}$ & $\begin{array}{r}5 \\
5 \\
- \\
- \\
- \\
- \\
- \\
- \\
-\end{array}$ & $\begin{array}{l}- \\
- \\
- \\
- \\
- \\
- \\
-\end{array}$ \\
\hline $\begin{array}{l}\text { Pacific } \\
\text { Alaska } \\
\text { California } \\
\text { Hawaii } \\
\text { Oregon } \\
\text { Washington }\end{array}$ & $\begin{array}{r}726 \\
9 \\
372 \\
22 \\
213 \\
110\end{array}$ & $\begin{array}{r}456 \\
8 \\
345 \\
22 \\
15 \\
66\end{array}$ & $\begin{array}{r}270 \\
1 \\
27 \\
- \\
198 \\
44\end{array}$ & $\begin{array}{l}\frac{20}{15} \\
\frac{-}{5}\end{array}$ & $\begin{array}{r}380 \\
1 \\
138 \\
219 \\
3 \\
19\end{array}$ & $\begin{array}{l}2 \\
- \\
- \\
-\end{array}$ & $\begin{array}{l}- \\
- \\
- \\
-\end{array}$ \\
\hline $\begin{array}{l}\text { Territories } \\
\text { American Samoa } \\
\text { C.N.M.I. } \\
\text { Guam } \\
\text { Puerto Rico } \\
\text { U.S. Virgin Islands }\end{array}$ & $\begin{array}{l}\mathrm{N} \\
- \\
- \\
-\end{array}$ & $\begin{array}{l}\mathrm{N} \\
- \\
- \\
-\end{array}$ & $\begin{array}{l}\mathrm{N} \\
- \\
- \\
-\end{array}$ & $\begin{array}{l}\mathrm{N} \\
- \\
- \\
-\end{array}$ & $\begin{array}{r}- \\
- \\
58 \\
3\end{array}$ & $\begin{array}{l}- \\
- \\
-\end{array}$ & $\begin{array}{l}- \\
- \\
-\end{array}$ \\
\hline
\end{tabular}

N: Not Reportable U: Unavailable —: No reported cases C.N.M.I.: Commonwealth of Northern Mariana Islands

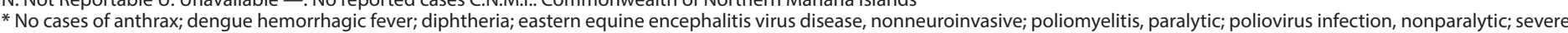

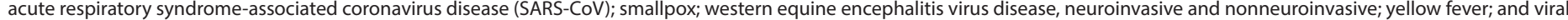
hemorrhagic fevers were reported in the United States during 2015.

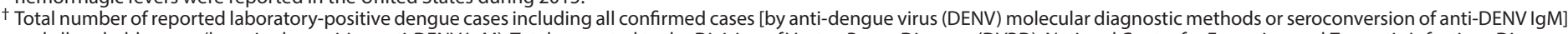

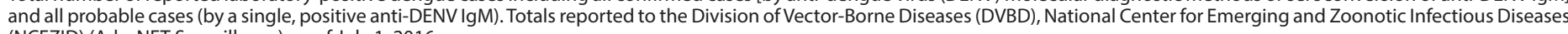
(NCEZID) (ArboNET Surveillance), as of July 1, 2016. 
Morbidity and Mortality Weekly Report

TABLE 2f. Reported cases of notifiable diseases, ${ }^{*}$ by geographic division and area — United States and U.S. territories, 2015

\begin{tabular}{|c|c|c|c|c|c|c|}
\hline \multirow[b]{2}{*}{ Area } & \multicolumn{4}{|c|}{ Ehrlichiosis and Anaplasmosis } & \multirow[b]{2}{*}{ Giardiasis } & \multirow[b]{2}{*}{ Gonorrhea $^{\dagger}$} \\
\hline & $\begin{array}{c}\text { Anaplasma } \\
\text { phagocytophilum } \\
\text { infection }\end{array}$ & $\begin{array}{c}\text { Ehrlichia chaffeensis } \\
\text { infection }\end{array}$ & $\begin{array}{c}\text { Ehrlichia ewingii } \\
\text { infection }\end{array}$ & $\begin{array}{l}\text { Undetermined } \\
\text { ehrlichiosis/ } \\
\text { anaplasmosis } \\
\end{array}$ & & \\
\hline United States & 3,656 & 1,288 & 14 & 179 & 14,485 & 395,216 \\
\hline $\begin{array}{l}\text { New England } \\
\text { Connecticut } \\
\text { Maine } \\
\text { Massachusetts } \\
\text { New Hampshire } \\
\text { Rhode Island } \\
\text { Vermont }\end{array}$ & $\begin{array}{r}1,438 \\
120 \\
186 \\
767 \\
110 \\
116 \\
139\end{array}$ & $\begin{array}{r}77 \\
5 \\
12 \\
12 \\
44 \\
4\end{array}$ & $\begin{array}{r}1 \\
\mathrm{~N} \\
- \\
-1 \\
- \\
-\end{array}$ & $\begin{array}{r}3 \\
\mathrm{~N} \\
1 \\
- \\
- \\
2\end{array}$ & $\begin{array}{r}1,151 \\
215 \\
116 \\
678 \\
102 \\
40 \\
\mathrm{~N}\end{array}$ & $\begin{array}{r}7,302 \\
2,088 \\
417 \\
3,817 \\
245 \\
580 \\
155\end{array}$ \\
\hline $\begin{array}{l}\text { Mid. Atlantic } \\
\text { New Jersey } \\
\text { New York (Upstate) } \\
\text { New York City } \\
\text { Pennsylvania }\end{array}$ & $\begin{array}{r}929 \\
125 \\
727 \\
56 \\
21\end{array}$ & $\begin{array}{r}181 \\
61 \\
109 \\
7 \\
4\end{array}$ & $\begin{array}{r}1 \\
1 \\
- \\
- \\
-\end{array}$ & $\begin{array}{r}26 \\
5 \\
11 \\
\frac{1}{10}\end{array}$ & $\begin{array}{r}2,835 \\
443 \\
860 \\
871 \\
661\end{array}$ & $\begin{array}{r}45,580 \\
7,228 \\
8,719 \\
16,842 \\
12,791\end{array}$ \\
\hline $\begin{array}{l}\text { E. N. Central } \\
\text { Illinois } \\
\text { Indiana } \\
\text { Michigan } \\
\text { Ohio } \\
\text { Wisconsin }\end{array}$ & $\begin{array}{r}563 \\
10 \\
-6 \\
1 \\
546\end{array}$ & $\begin{array}{r}74 \\
30 \\
- \\
5 \\
17 \\
22\end{array}$ & $\begin{array}{l}- \\
- \\
- \\
-\end{array}$ & $\begin{array}{r}82 \\
1 \\
20 \\
- \\
1 \\
60\end{array}$ & $\begin{array}{r}1,493 \\
N \\
178 \\
444 \\
383 \\
488\end{array}$ & $\begin{array}{r}57,127 \\
17,130 \\
7,843 \\
10,330 \\
16,564 \\
5,260\end{array}$ \\
\hline $\begin{array}{l}\text { W.N. Central } \\
\text { lowa } \\
\text { Kansas } \\
\text { Minnesota } \\
\text { Missouri } \\
\text { Nebraska } \\
\text { North Dakota } \\
\text { South Dakota }\end{array}$ & $\begin{array}{r}637 \\
\mathrm{~N} \\
5 \\
613 \\
15 \\
1 \\
3 \\
-\end{array}$ & $\begin{array}{r}286 \\
\mathrm{~N} \\
46 \\
4 \\
231 \\
4 \\
1 \\
-\end{array}$ & $\begin{array}{r}9 \\
N \\
2 \\
- \\
-7 \\
- \\
-\end{array}$ & $\begin{array}{r}32 \\
\mathrm{~N} \\
1 \\
21 \\
9 \\
-1 \\
-\end{array}$ & $\begin{array}{r}1,487 \\
213 \\
108 \\
617 \\
251 \\
131 \\
39 \\
128\end{array}$ & $\begin{array}{r}21,257 \\
2,247 \\
2,536 \\
4,097 \\
8,942 \\
1,703 \\
684 \\
1,048\end{array}$ \\
\hline $\begin{array}{l}\text { S. Atlantic } \\
\text { Delaware } \\
\text { District of Columbia } \\
\text { Florida } \\
\text { Georgia } \\
\text { Maryland } \\
\text { North Carolina } \\
\text { South Carolina } \\
\text { Virginia } \\
\text { West Virginia }\end{array}$ & $\begin{array}{r}43 \\
4 \\
\mathrm{~N} \\
5 \\
- \\
4 \\
19 \\
1 \\
10 \\
-\end{array}$ & $\begin{array}{r}274 \\
14 \\
1 \\
18 \\
33 \\
30 \\
74 \\
3 \\
96 \\
5\end{array}$ & $\begin{array}{l}- \\
- \\
- \\
- \\
- \\
-\end{array}$ & $\begin{array}{r}13 \\
- \\
1 \\
1 \\
- \\
- \\
10 \\
1\end{array}$ & $\begin{array}{r}2,634 \\
28 \\
121 \\
1,038 \\
736 \\
251 \\
\mathrm{~N} \\
125 \\
269 \\
66\end{array}$ & $\begin{array}{r}87,900 \\
1,310 \\
2,742 \\
24,125 \\
15,982 \\
6,858 \\
19,809 \\
8,206 \\
8,099 \\
769\end{array}$ \\
\hline $\begin{array}{l}\text { E.S. Central } \\
\text { Alabama } \\
\text { Kentucky } \\
\text { Mississippi } \\
\text { Tennessee }\end{array}$ & $\begin{array}{r}17 \\
7 \\
- \\
10\end{array}$ & $\begin{array}{r}132 \\
9 \\
53 \\
9 \\
61\end{array}$ & $\frac{1}{-}$ & $\begin{array}{r}16 \\
2 \\
- \\
3 \\
11\end{array}$ & $\begin{array}{r}188 \\
188 \\
N \\
N \\
N\end{array}$ & $\begin{array}{r}26,035 \\
7,196 \\
4,678 \\
5,775 \\
8,386\end{array}$ \\
\hline $\begin{array}{l}\text { W.S. Central } \\
\text { Arkansas } \\
\text { Louisiana } \\
\text { Oklahoma } \\
\text { Texas }\end{array}$ & $\begin{array}{l}19 \\
\frac{16}{-} \\
\frac{3}{3}\end{array}$ & $\begin{array}{r}264 \\
192 \\
2 \\
62 \\
8\end{array}$ & $\begin{array}{r}2 \\
1 \\
-1 \\
-\end{array}$ & $\begin{array}{r}\frac{2}{2} \\
- \\
-\end{array}$ & $\begin{array}{r}352 \\
119 \\
233 \\
\mathrm{~N} \\
\mathrm{~N}\end{array}$ & $\begin{array}{r}61,321 \\
4,780 \\
10,282 \\
6,542 \\
39,717\end{array}$ \\
\hline $\begin{array}{l}\text { Mountain } \\
\text { Arizona } \\
\text { Colorado } \\
\text { Idaho } \\
\text { Montana } \\
\text { Nevada } \\
\text { New Mexico } \\
\text { Utah } \\
\text { Wyoming }\end{array}$ & $\begin{array}{l}3 \\
\mathrm{~N} \\
\mathrm{~N} \\
1 \\
-\mathrm{N} \\
2 \\
-\end{array}$ & $\begin{array}{l}- \\
\bar{N} \\
\mathrm{~N} \\
- \\
\bar{N} \\
- \\
-\end{array}$ & $\begin{array}{l}- \\
N \\
N \\
- \\
-N \\
-\end{array}$ & $\begin{array}{l}3 \\
3 \\
\mathrm{~N} \\
\mathrm{~N} \\
- \\
\mathrm{N} \\
- \\
-\end{array}$ & $\begin{array}{r}1,128 \\
143 \\
370 \\
161 \\
93 \\
53 \\
77 \\
196 \\
35\end{array}$ & \begin{tabular}{r|}
21,804 \\
8,245 \\
4,387 \\
472 \\
844 \\
3,630 \\
2,489 \\
1,562 \\
175
\end{tabular} \\
\hline $\begin{array}{l}\text { Pacific } \\
\text { Alaska } \\
\text { California } \\
\text { Hawaii } \\
\text { Oregon } \\
\text { Washington }\end{array}$ & $\begin{array}{c}7 \\
N \\
3 \\
N \\
3 \\
1\end{array}$ & $\begin{array}{l}\bar{N} \\
\bar{N} \\
-\end{array}$ & $\begin{array}{l}\bar{N} \\
\bar{N} \\
-\end{array}$ & $\begin{array}{r}2 \\
\mathrm{~N} \\
1 \\
\mathrm{~N} \\
1 \\
-\end{array}$ & $\begin{array}{r}3,217 \\
94 \\
2,150 \\
38 \\
334 \\
601\end{array}$ & $\begin{array}{r}66,890 \\
1,113 \\
54,135 \\
1,239 \\
3,232 \\
7,171\end{array}$ \\
\hline \multicolumn{7}{|l|}{ Territories } \\
\hline $\begin{array}{l}\text { American Samoa } \\
\text { C.N.M.I. } \\
\text { Guam } \\
\text { Puerto Rico } \\
\text { U.S. Virgin Islands }\end{array}$ & $\begin{array}{l}\mathrm{N} \\
\mathrm{N} \\
\mathrm{N} \\
-\end{array}$ & $\begin{array}{l}\mathrm{N} \\
\mathrm{N} \\
\mathrm{N} \\
-\end{array}$ & $\begin{array}{l}\mathrm{N} \\
\mathrm{N} \\
\mathrm{N} \\
-\end{array}$ & $\begin{array}{l}\mathrm{N} \\
\mathrm{N} \\
\mathrm{N} \\
-\end{array}$ & $\begin{array}{r}- \\
\overline{1} \\
23 \\
-\end{array}$ & $\begin{array}{r}- \\
\overline{147} \\
620 \\
52\end{array}$ \\
\hline
\end{tabular}

N: Not Reportable U: Unavailable —: No reported cases C.N.M.I.: Commonwealth of Northern Mariana Islands

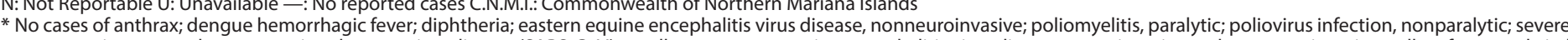

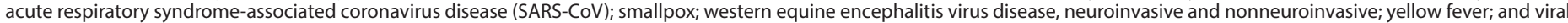
hemorrhagic fevers were reported in the United States during 2015.

† Totals reported to the Division of STD Prevention (DSTDP), National Center for HIV/AIDS, Viral Hepatitis, STD, and TB Prevention (NCHHSTP), as of June 8, 2016. 
TABLE 2g. Reported cases of notifiable diseases, ${ }^{*}$ by geographic division and area — United States and U.S. territories, 2015

\begin{tabular}{|c|c|c|c|c|c|c|c|c|}
\hline \multirow[b]{3}{*}{ Area } & \multicolumn{5}{|c|}{ Haemophilus influenzae, invasive disease } & \multirow{3}{*}{$\begin{array}{c}\text { Hansen's disease } \\
\text { (leprosy) }\end{array}$} & \multicolumn{2}{|c|}{ Hantavirus infections } \\
\hline & \multirow{2}{*}{$\begin{array}{l}\text { All ages, } \\
\text { serotype }\end{array}$} & \multicolumn{4}{|c|}{ Age $<5$ years } & & \multirow{2}{*}{$\begin{array}{c}\text { Hantavirus } \\
\text { infection } \\
\text { (non-HPS) } \\
\end{array}$} & \multirow{2}{*}{$\begin{array}{c}\text { Hantavirus } \\
\text { pulmonary } \\
\text { syndrome (HPS) }\end{array}$} \\
\hline & & Serotype b & Not typeable & Non-b serotype & Unknown & & & \\
\hline United States & 4,138 & 29 & 175 & 135 & 167 & 89 & 3 & 21 \\
\hline New England & 259 & 1 & 8 & 9 & 1 & 1 & - & - \\
\hline Connecticut & 42 & - & - & 3 & - & - & $\mathrm{N}$ & $\mathrm{N}$ \\
\hline Maine & 39 & 1 & 1 & 1 & - & $\mathrm{N}$ & - & - \\
\hline Massachusetts & 122 & - & 4 & 5 & - & - & - & - \\
\hline New Hampshire & 23 & - & 1 & - & 1 & 1 & - & - \\
\hline Rhode Island & 20 & - & 1 & - & - & - & - & - \\
\hline Vermont & 13 & - & 1 & - & - & $\mathrm{N}$ & - & - \\
\hline Mid. Atlantic & 633 & 2 & 14 & 4 & 29 & 7 & - & - \\
\hline New Jersey & 136 & - & - & - & 18 & 1 & $\mathrm{~N}$ & - \\
\hline New York (Upstate) & 197 & 1 & 9 & 2 & - & - & - & - \\
\hline New York City & 97 & - & - & - & 6 & 3 & - & - \\
\hline Pennsylvania & 203 & 1 & 5 & 2 & 5 & 3 & - & - \\
\hline E. N. Central & 723 & 8 & 39 & 20 & 8 & 4 & 2 & 1 \\
\hline Illinois & 204 & 1 & 12 & 6 & 3 & - & 1 & - \\
\hline Indiana & 119 & 4 & 4 & 3 & 1 & 1 & - & 1 \\
\hline Michigan & 132 & - & 5 & 6 & 2 & 1 & - & - \\
\hline Ohio & 161 & 2 & 12 & 3 & - & 2 & - & - \\
\hline Wisconsin & 107 & 1 & 6 & 2 & 2 & - & 1 & - \\
\hline W.N. Central & 334 & 1 & 3 & 12 & 26 & 1 & - & 1 \\
\hline lowa & 2 & - & - & - & - & - & - & - \\
\hline Kansas & 48 & - & 3 & 5 & - & - & $\mathrm{N}$ & - \\
\hline Minnesota & 105 & - & - & - & 11 & 1 & - & - \\
\hline Missouri & 121 & - & - & - & 14 & - & - & - \\
\hline Nebraska & 32 & - & - & 4 & 1 & - & - & - \\
\hline North Dakota & 25 & 1 & - & 3 & - & $\mathrm{N}$ & - & 1 \\
\hline South Dakota & 1 & - & - & - & - & - & - & - \\
\hline S. Atlantic & 1,009 & 2 & 48 & 25 & 40 & 36 & - & - \\
\hline Delaware & 18 & - & - & - & 3 & - & - & - \\
\hline District of Columbia & 9 & - & 1 & - & - & - & $\mathrm{N}$ & - \\
\hline Florida & 239 & - & 24 & 7 & 6 & 29 & - & - \\
\hline Georgia & 210 & 1 & 10 & 8 & 6 & 3 & - & - \\
\hline Maryland & 85 & - & 4 & 2 & - & - & - & - \\
\hline North Carolina & 182 & - & - & - & 20 & 1 & - & - \\
\hline South Carolina & 100 & - & 2 & 5 & 5 & 1 & - & - \\
\hline Virginia & 121 & 1 & 5 & 3 & - & 2 & $\mathrm{~N}$ & - \\
\hline West Virginia & 45 & - & 2 & - & - & $\mathrm{N}$ & - & - \\
\hline E.S. Central & 320 & - & 13 & 12 & 6 & 2 & - & - \\
\hline Alabama & 80 & - & 3 & 2 & 1 & 1 & $\mathrm{~N}$ & $\mathrm{~N}$ \\
\hline Kentucky & 49 & - & 1 & 1 & 3 & - & - & - \\
\hline Mississippi & 45 & - & - & 4 & - & 1 & - & - \\
\hline Tennessee & 146 & - & 9 & 5 & 2 & - & - & - \\
\hline W.S. Central & 245 & 4 & 17 & 10 & 3 & 22 & - & 2 \\
\hline Arkansas & 56 & - & 6 & 3 & 1 & 2 & - & - \\
\hline Louisiana & 61 & - & 1 & 3 & 2 & - & - & - \\
\hline Oklahoma & 117 & - & 10 & 4 & - & $\mathrm{N}$ & $\mathrm{N}$ & - \\
\hline Texas & 11 & 4 & $\mathrm{~N}$ & $\mathrm{~N}$ & $\mathrm{~N}$ & 20 & - & 2 \\
\hline Mountain & 415 & 9 & 27 & 34 & 5 & 2 & 1 & 14 \\
\hline Arizona & 133 & 3 & 13 & 18 & 2 & 1 & - & 1 \\
\hline Colorado & 92 & 1 & 5 & 2 & 1 & - & - & 6 \\
\hline Idaho & 27 & 1 & 3 & 1 & 1 & - & $\mathrm{N}$ & - \\
\hline Montana & 15 & - & - & 2 & - & - & - & 4 \\
\hline Nevada & 31 & 2 & - & - & - & - & - & - \\
\hline New Mexico & 62 & 1 & 1 & 8 & - & - & - & 1 \\
\hline Utah & 50 & - & 5 & 3 & 1 & 1 & 1 & 1 \\
\hline Wyoming & 5 & 1 & - & - & - & - & - & 1 \\
\hline Pacific & 200 & 2 & 6 & 9 & 49 & 14 & - & 3 \\
\hline Alaska & 22 & 1 & 1 & 5 & - & - & - & - \\
\hline California & 64 & - & - & - & 46 & 7 & - & 2 \\
\hline Hawaii & 12 & - & - & - & 3 & 7 & - & - \\
\hline Oregon & 97 & - & 3 & 2 & - & $\mathrm{N}$ & - & - \\
\hline Washington & 5 & 1 & 2 & 2 & - & $\mathrm{N}$ & $\mathrm{N}$ & 1 \\
\hline Territories & & & & & & & & \\
\hline American Samoa & - & - & - & - & - & - & - & $\mathrm{N}$ \\
\hline $\begin{array}{l}\text { C.N.M.I. } \\
\text { lat }\end{array}$ & - & - & - & - & - & - & - & - \\
\hline Guam & - & - & - & - & - & 22 & - & $\mathrm{N}$ \\
\hline Puerto Rico & - & - & - & - & - & - & - & - \\
\hline U.S. Virgin Islands & - & - & - & - & - & - & - & - \\
\hline
\end{tabular}

N: Not Reportable U: Unavailable -: No reported cases C.N.M.I.: Commonwealth of Northern Mariana Islands

* No cases of anthrax; dengue hemorrhagic fever; diphtheria; eastern equine encephalitis virus disease, nonneuroinvasive; poliomyelitis, paralytic; poliovirus infection, nonparalytic; severe

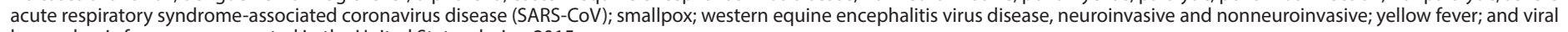
hemorrhagic fevers were reported in the United States during 2015. 
Morbidity and Mortality Weekly Report

TABLE $2 \mathrm{~h}$. Reported cases of notifiable diseases, ${ }^{*}$ by geographic division and area - United States and U.S. territories, 2015

\begin{tabular}{|c|c|c|c|c|c|c|c|}
\hline \multirow[b]{2}{*}{ Area } & \multirow{2}{*}{$\begin{array}{l}\text { Hemolytic } \\
\text { uremic syndrome } \\
\text { postdiarrheal }\end{array}$} & \multicolumn{6}{|c|}{ Hepatitis } \\
\hline & & A acute & B acute & B chronic ${ }^{\dagger}$ & B perinatal infection & C acute & $C$, past or present ${ }^{\dagger}$ \\
\hline United States & 274 & 1,390 & 3,370 & 14,147 & 37 & 2,447 & 179,584 \\
\hline $\begin{array}{l}\text { New England } \\
\text { Connecticut } \\
\text { Maine } \\
\text { Massachusetts } \\
\text { New Hampshire } \\
\text { Rhode Island } \\
\text { Vermont }\end{array}$ & $\begin{array}{r}11 \\
2 \\
7 \\
1 \\
-1 \\
-\end{array}$ & $\begin{array}{r}60 \\
9 \\
8 \\
34 \\
2 \\
4 \\
3\end{array}$ & $\begin{array}{r}43 \\
6 \\
9 \\
25 \\
U \\
3\end{array}$ & $\begin{array}{r}412 \\
38 \\
51 \\
284 \\
\mathrm{U} \\
39\end{array}$ & $\begin{array}{r}2 \\
1 \\
-1 \\
- \\
-\end{array}$ & $\begin{array}{r}295 \\
15 \\
30 \\
249 \\
\mathrm{~N} \\
\mathrm{U} \\
1\end{array}$ & $\begin{array}{r}11,067 \\
3,291 \\
1,486 \\
5,482 \\
\mathrm{~N} \\
- \\
808\end{array}$ \\
\hline $\begin{array}{l}\text { Mid. Atlantic } \\
\text { New Jersey } \\
\text { New York (Upstate) } \\
\text { New York City } \\
\text { Pennsylvania }\end{array}$ & $\begin{array}{r}16 \\
2 \\
7 \\
5 \\
2\end{array}$ & $\begin{array}{r}225 \\
59 \\
50 \\
73 \\
43\end{array}$ & $\begin{array}{r}226 \\
85 \\
32 \\
48 \\
61\end{array}$ & $\begin{array}{r}3,445 \\
273 \\
561 \\
1,754 \\
857\end{array}$ & $\begin{array}{r}\frac{4}{-} \\
- \\
-\end{array}$ & $\begin{array}{r}380 \\
130 \\
112 \\
9 \\
129\end{array}$ & $\begin{array}{r}34,974 \\
7,928 \\
8,335 \\
6,723 \\
11,988\end{array}$ \\
\hline $\begin{array}{l}\text { E. N. Central } \\
\text { Illinois } \\
\text { Indiana } \\
\text { Michigan } \\
\text { Ohio } \\
\text { Wisconsin }\end{array}$ & $\begin{array}{r}39 \\
3 \\
10 \\
12 \\
3 \\
11\end{array}$ & $\begin{array}{r}172 \\
57 \\
19 \\
51 \\
36 \\
9\end{array}$ & $\begin{array}{r}658 \\
55 \\
133 \\
56 \\
409 \\
5\end{array}$ & $\begin{array}{r}1,748 \\
440 \\
68 \\
350 \\
890 \\
-\end{array}$ & $\begin{array}{l}\frac{2}{-} \\
- \\
-\end{array}$ & $\begin{array}{r}438 \\
31 \\
138 \\
83 \\
122 \\
64\end{array}$ & $\begin{array}{r}34,672 \\
8,696 \\
\mathrm{~N} \\
6,808 \\
19,165 \\
3\end{array}$ \\
\hline $\begin{array}{l}\text { W.N. Central } \\
\text { lowa } \\
\text { Kansas } \\
\text { Minnesota } \\
\text { Missouri } \\
\text { Nebraska } \\
\text { North Dakota } \\
\text { South Dakota }\end{array}$ & $\begin{array}{r}39 \\
5 \\
5 \\
10 \\
14 \\
1 \\
3 \\
1\end{array}$ & $\begin{array}{r}66 \\
16 \\
7 \\
21 \\
21 \\
9 \\
6 \\
5 \\
2\end{array}$ & $\begin{array}{r}96 \\
16 \\
19 \\
19 \\
35 \\
3 \\
2 \\
2\end{array}$ & $\begin{array}{r}1,045 \\
39 \\
130 \\
186 \\
521 \\
93 \\
53 \\
23\end{array}$ & $\begin{array}{l}\frac{4}{-} \\
\frac{3}{-} \\
-1 \\
-\end{array}$ & $\begin{array}{r}75 \\
U \\
22 \\
37 \\
8 \\
8 \\
- \\
-\end{array}$ & $\begin{array}{r}13,786 \\
20 \\
1,697 \\
2,015 \\
7,800 \\
893 \\
794 \\
567\end{array}$ \\
\hline $\begin{array}{l}\text { S. Atlantic } \\
\text { Delaware } \\
\text { District of Columbia } \\
\text { Florida } \\
\text { Georgia } \\
\text { Maryland } \\
\text { North Carolina } \\
\text { South Carolina } \\
\text { Virginia } \\
\text { West Virginia }\end{array}$ & $\begin{array}{l}24 \\
- \\
5 \\
5 \\
2 \\
3 \\
4 \\
4 \\
1\end{array}$ & $\begin{array}{r}278 \\
2 \\
U \\
108 \\
30 \\
19 \\
45 \\
16 \\
50 \\
8\end{array}$ & $\begin{array}{r}1,135 \\
8 \\
U \\
432 \\
119 \\
40 \\
165 \\
30 \\
69 \\
272\end{array}$ & $\begin{array}{r}5,422 \\
122 \\
U \\
1,423 \\
1,867 \\
566 \\
507 \\
156 \\
556 \\
225\end{array}$ & $\begin{array}{r}\frac{6}{U} \\
\frac{-}{2} \\
\frac{1}{1} \\
\frac{1}{2}\end{array}$ & $\begin{array}{r}512 \\
U \\
U \\
126 \\
84 \\
38 \\
144 \\
5 \\
52 \\
63\end{array}$ & $\begin{array}{r}56,385 \\
U \\
U \\
22,793 \\
7,175 \\
7,425 \\
N \\
4,515 \\
8,138 \\
6,339\end{array}$ \\
\hline $\begin{array}{l}\text { E.S. Central } \\
\text { Alabama } \\
\text { Kentucky } \\
\text { Mississippi } \\
\text { Tennessee }\end{array}$ & $\begin{array}{r}28 \\
3 \\
9 \\
1 \\
15\end{array}$ & $\begin{array}{r}55 \\
23 \\
16 \\
2 \\
14\end{array}$ & $\begin{array}{r}556 \\
101 \\
162 \\
50 \\
243\end{array}$ & $\begin{array}{l}-\bar{N} \\
N \\
N \\
N\end{array}$ & $\begin{array}{r}1 \\
1 \\
- \\
- \\
-\end{array}$ & $\begin{array}{r}362 \\
70 \\
119 \\
U \\
173\end{array}$ & $\begin{array}{l}\bar{N} \\
\mathrm{~N} \\
\bar{N}\end{array}$ \\
\hline $\begin{array}{l}\text { W.S. Central } \\
\text { Arkansas } \\
\text { Louisiana } \\
\text { Oklahoma } \\
\text { Texas }\end{array}$ & $\begin{array}{r}39 \\
5 \\
3 \\
17 \\
14\end{array}$ & $\begin{array}{r}173 \\
10 \\
5 \\
11 \\
147\end{array}$ & $\begin{array}{r}319 \\
36 \\
87 \\
37 \\
159\end{array}$ & $\begin{array}{r}285 \\
N \\
201 \\
84 \\
N\end{array}$ & $\frac{1}{-}$ & $\begin{array}{r}109 \\
2 \\
24 \\
35 \\
48\end{array}$ & $\begin{array}{r}3,068 \\
N \\
2,478 \\
590 \\
N\end{array}$ \\
\hline $\begin{array}{l}\text { Mountain } \\
\text { Arizona } \\
\text { Colorado } \\
\text { Idaho } \\
\text { Montana } \\
\text { Nevada } \\
\text { New Mexico } \\
\text { Utah } \\
\text { Wyoming }\end{array}$ & $\begin{array}{r}25 \\
2 \\
4 \\
6 \\
2 \\
7 \\
- \\
4 \\
-\end{array}$ & $\begin{array}{r}118 \\
54 \\
25 \\
9 \\
2 \\
11 \\
6 \\
8 \\
3\end{array}$ & $\begin{array}{r}102 \\
25 \\
28 \\
8 \\
4 \\
25 \\
2 \\
10 \\
\mathrm{U}\end{array}$ & $\begin{array}{r}525 \\
133 \\
163 \\
51 \\
31 \\
41 \\
64 \\
42\end{array}$ & $\begin{array}{l}2 \\
-1 \\
- \\
-1 \\
- \\
-\end{array}$ & $\begin{array}{r}141 \\
\text { U } \\
40 \\
4 \\
15 \\
12 \\
40 \\
30 \\
\text { U }\end{array}$ & $\begin{array}{r}11,662 \\
U \\
3,561 \\
1,017 \\
1,354 \\
- \\
3,680 \\
1,578 \\
472\end{array}$ \\
\hline $\begin{array}{l}\text { Pacific } \\
\text { Alaska } \\
\text { California } \\
\text { Hawaii } \\
\text { Oregon } \\
\text { Washington } \\
\end{array}$ & $\begin{array}{l}\frac{53}{38} \\
\frac{1}{15} \\
\mathrm{~N}\end{array}$ & $\begin{array}{r}243 \\
4 \\
179 \\
6 \\
28 \\
26\end{array}$ & $\begin{array}{r}235 \\
3 \\
160 \\
14 \\
24 \\
34\end{array}$ & $\begin{array}{r}1,265 \\
- \\
1,008 \\
U \\
138 \\
119\end{array}$ & $\begin{array}{r}15 \\
11 \\
1 \\
2 \\
1\end{array}$ & $\begin{array}{r}135 \\
\mathrm{~N} \\
59 \\
- \\
13 \\
63\end{array}$ & $\begin{array}{r}13,970 \\
1,604 \\
1,182 \\
U \\
5,472 \\
5,712\end{array}$ \\
\hline $\begin{array}{l}\text { Territories } \\
\text { American Samoa } \\
\text { C.N.M.I. } \\
\text { Guam } \\
\text { Puerto Rico } \\
\text { U.S. Virgin Islands }\end{array}$ & $\begin{array}{l}\mathrm{N} \\
\frac{\mathrm{N}}{\mathrm{N}} \\
-\end{array}$ & $\begin{array}{r}- \\
48 \\
2 \\
-\end{array}$ & $\begin{array}{l}- \\
\frac{-}{24} \\
-\end{array}$ & $\begin{array}{r}\mathrm{N} \\
- \\
113 \\
9 \\
-\end{array}$ & $\begin{array}{l}- \\
- \\
-\end{array}$ & $\begin{array}{l}- \\
\bar{N} \\
-\end{array}$ & $\begin{array}{r}- \\
138 \\
960 \\
-\end{array}$ \\
\hline
\end{tabular}

N: Not Reportable U: Unavailable -: No reported cases C.N.M.I.: Commonwealth of Northern Mariana Islands

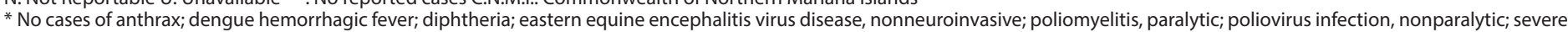

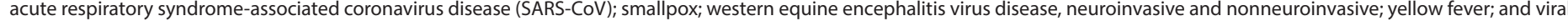
hemorrhagic fevers were reported in the United States during 2015.

† Reported cases of hepatitis B, chronic and hepatitis C, past or present may not reflect unique case reports and may include both confirmed and probable case reports. 
Morbidity and Mortality Weekly Report

TABLE 2i. Reported cases of notifiable diseases, ${ }^{*}$ by geographic division and area - United States and U.S. territories, 2015

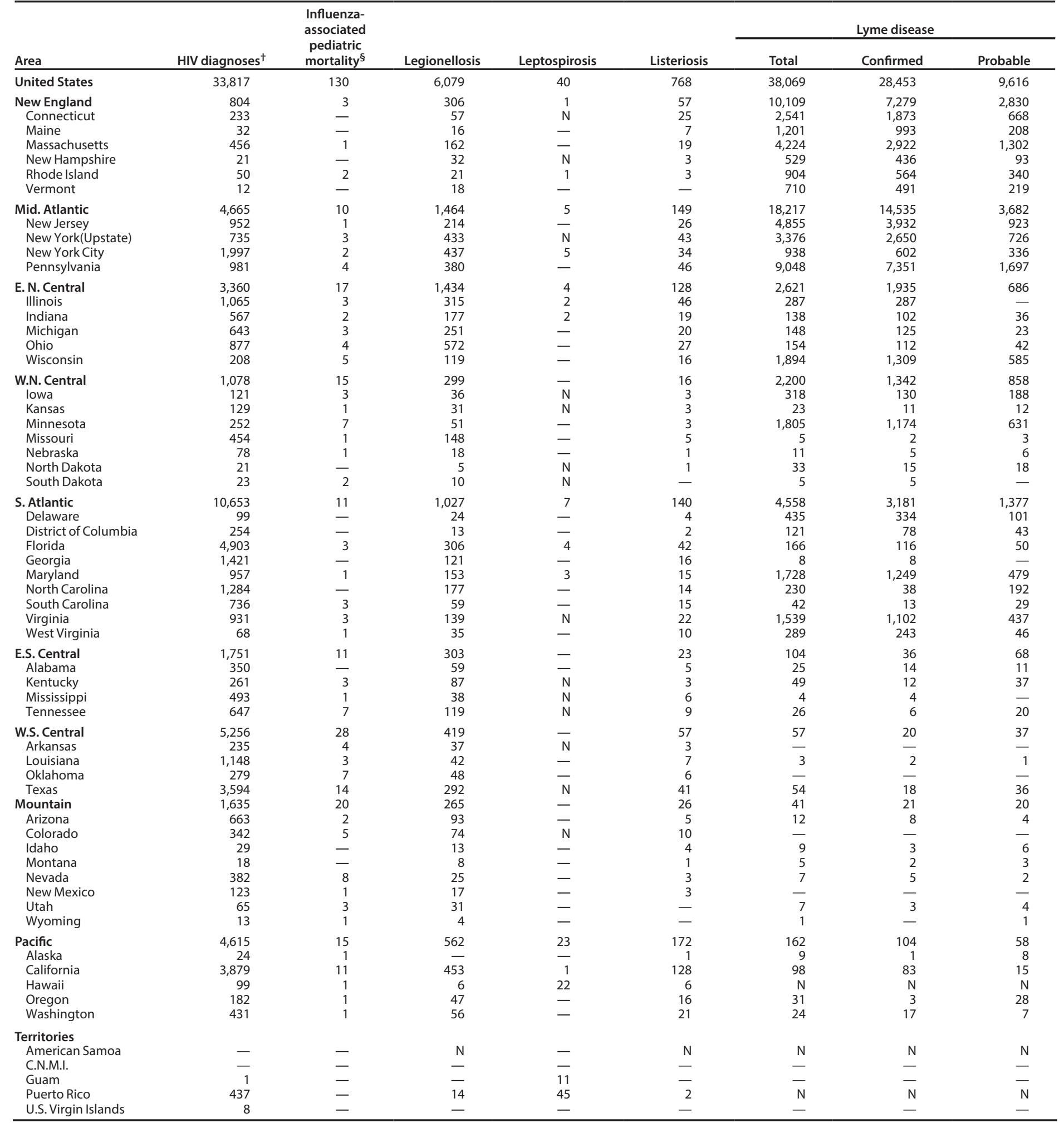

N: Not Reportable U: Unavailable —: No reported cases C.N.M.I.: Commonwealth of Northern Mariana Islands

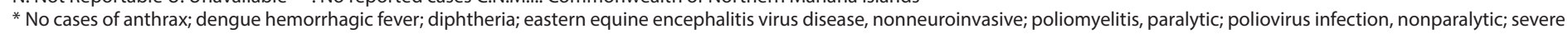

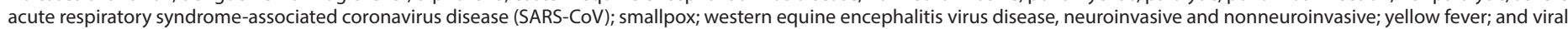
hemorrhagic fevers were reported in the United States during 2015.

† Total number of HIV diagnoses reported to the Division of HIV/AIDS Prevention, NCHHSTP through December 31, 2015.

$\S$ Totals reported to the Influenza Division (ID), National Center for Immunization and Respiratory Diseases (NCIRD), as of June 30, 2016. 
TABLE 2j. Reported cases of notifiable diseases, ${ }^{*}$ by geographic division and area - United States and U.S. territories, 2015

\begin{tabular}{|c|c|c|c|c|c|c|c|c|c|}
\hline \multirow[b]{2}{*}{ Area } & \multirow[b]{2}{*}{ Malaria } & \multicolumn{3}{|c|}{ Measles } & \multicolumn{5}{|c|}{ Meningococcal disease } \\
\hline & & Total & Indigenous & Imported & All serogroups & $\begin{array}{c}\text { Serogroup } A, C, Y, \\
\text { and } W-135\end{array}$ & Serogroup B & $\begin{array}{c}\begin{array}{c}\text { Serogroups } \\
\text { Other }\end{array} \\
\end{array}$ & $\begin{array}{c}\text { Serogroups } \\
\text { Unknown }\end{array}$ \\
\hline United States & 1,390 & 188 & 162 & 26 & 372 & 120 & 111 & 21 & 120 \\
\hline $\begin{array}{l}\text { New England } \\
\text { Connecticut }\end{array}$ & $\begin{array}{l}92 \\
12\end{array}$ & $=$ & - & - & $\begin{array}{r}27 \\
5\end{array}$ & $\begin{array}{l}7 \\
1\end{array}$ & $\begin{array}{r}14 \\
2\end{array}$ & $\begin{array}{l}6 \\
2\end{array}$ & - \\
\hline Maine & 7 & - & - & - & 4 & - & 2 & 2 & - \\
\hline Massachusetts & 51 & - & - & - & 12 & 6 & 6 & - & - \\
\hline New Hampshire & 6 & - & - & - & 1 & - & - & 1 & - \\
\hline Rhode Island & 16 & - & - & - & 4 & - & 4 & - & - \\
\hline Vermont & - & - & - & - & 1 & - & - & 1 & - \\
\hline Mid. Atlantic & 381 & 11 & 4 & 7 & 34 & 4 & 13 & - & 17 \\
\hline New Jersey & 86 & 3 & 3 & - & 8 & - & - & - & 8 \\
\hline New York (Upstate) & 58 & 1 & - & 1 & 9 & 2 & 7 & - & - \\
\hline New York City & 200 & 6 & 1 & 5 & 8 & - & - & - & 8 \\
\hline Pennsylvania & 37 & 1 & - & 1 & 9 & 2 & 6 & - & 1 \\
\hline E. N. Central & $\begin{array}{r}121 \\
50\end{array}$ & $\begin{array}{l}19 \\
17\end{array}$ & 18 & 1 & $\begin{array}{l}56 \\
15\end{array}$ & $\begin{array}{l}20 \\
10\end{array}$ & 27 & $\begin{array}{l}5 \\
2\end{array}$ & 4 \\
\hline Indiana & $\begin{array}{r}50 \\
9\end{array}$ & - & - & - & $\begin{array}{r}15 \\
6\end{array}$ & - & $\begin{array}{l}3 \\
5\end{array}$ & $\begin{array}{l}2 \\
1\end{array}$ & - \\
\hline Michigan & 20 & 1 & 1 & - & 8 & 4 & 2 & - & 2 \\
\hline $\begin{array}{l}\text { Ohio } \\
\text { Ond }\end{array}$ & 37 & 1 & - & 1 & 18 & 3 & 13 & 2 & - \\
\hline Wisconsin & 5 & - & - & - & 9 & 3 & 4 & - & 2 \\
\hline W.N. Central & 98 & 8 & 5 & 3 & 27 & 3 & 2 & 1 & 21 \\
\hline lowa & 17 & - & - & - & 5 & - & 1 & 1 & 3 \\
\hline Kansas & 6 & - & - & - & 5 & 2 & 1 & - & 2 \\
\hline Minnesota & 43 & 2 & - & 2 & 7 & - & - & - & 7 \\
\hline Missouri & 19 & 1 & - & 1 & 7 & - & - & - & 7 \\
\hline Nebraska & 4 & 3 & 3 & - & 2 & - & - & - & 2 \\
\hline North Dakota & 5 & - & - & - & - & - & - & - & - \\
\hline South Dakota & 4 & 2 & 2 & - & 1 & 1 & - & - & - \\
\hline S. Atlantic & 336 & 11 & 5 & 6 & 66 & 31 & 16 & 5 & 14 \\
\hline Delaware & 3 & 1 & - & 1 & - & - & - & - & - \\
\hline District of Columbia & 17 & 3 & 2 & 1 & 3 & 1 & - & - & 2 \\
\hline Florida & 40 & 5 & 3 & 2 & 23 & 15 & 6 & 1 & 1 \\
\hline Georgia & 56 & 1 & - & 1 & 17 & 10 & 1 & - & 6 \\
\hline Maryland & 122 & - & - & - & 2 & 1 & 1 & - & - \\
\hline North Carolina & 27 & - & - & - & 6 & 3 & 2 & - & 1 \\
\hline South Carolina & 3 & - & - & - & 3 & - & - & 2 & 1 \\
\hline Virginia & 66 & 1 & - & 1 & 10 & - & 6 & 2 & 2 \\
\hline West Virginia & 2 & - & - & - & 2 & 1 & - & - & 1 \\
\hline E.S. Central & 31 & - & - & - & 13 & 3 & 5 & 1 & 4 \\
\hline Alabama & 11 & - & - & - & 6 & 2 & 3 & - & 1 \\
\hline Kentucky & 4 & - & - & - & 3 & - & - & - & 3 \\
\hline Mississippi & 1 & - & - & - & - & - & - & - & - \\
\hline Tennessee & 15 & - & - & - & 4 & 1 & 2 & 1 & - \\
\hline W.S. Central & 131 & 2 & - & 2 & 40 & 18 & 14 & - & 8 \\
\hline Arkansas & 9 & - & - & - & 2 & 2 & - & - & - \\
\hline Louisiana & 11 & - & - & - & 5 & 1 & 2 & - & 2 \\
\hline Oklahoma & 12 & 1 & - & 1 & 3 & 1 & 2 & - & - \\
\hline Texas & 99 & 1 & - & 1 & 30 & 14 & 10 & - & 6 \\
\hline Mountain & 58 & 18 & 17 & 1 & 15 & 9 & 2 & 3 & 1 \\
\hline Arizona & 14 & 7 & 7 & - & 5 & 3 & 1 & 1 & - \\
\hline Colorado & 21 & 1 & 1 & - & 4 & 2 & - & 1 & 1 \\
\hline Idaho & 6 & - & - & - & - & - & - & - & - \\
\hline Montana & 1 & - & - & - & 1 & 1 & - & - & - \\
\hline Nevada & 6 & 9 & 9 & - & 1 & - & - & 1 & - \\
\hline New Mexico & 3 & - & - & - & 1 & 1 & - & - & - \\
\hline Utah & 6 & 1 & - & 1 & 2 & 1 & 1 & - & - \\
\hline Wyoming & 1 & - & - & - & 1 & 1 & - & - & - \\
\hline Pacific & 142 & 119 & 113 & 6 & 94 & 25 & 18 & - & 51 \\
\hline Alaska & 3 & - & - & - & 4 & 4 & - & - & - \\
\hline California & 97 & 109 & 103 & 6 & 46 & - & - & - & 46 \\
\hline Hawaii & 1 & - & - & - & 4 & 1 & 1 & - & 2 \\
\hline Oregon & 20 & - & - & - & 30 & 13 & 14 & - & 3 \\
\hline Washington & 21 & 10 & 10 & - & 10 & 7 & 3 & - & - \\
\hline \multicolumn{10}{|l|}{ Territories } \\
\hline American Samoa & - & - & - & - & - & - & - & - & - \\
\hline C.N.M.I. & - & - & - & - & - & - & - & - & - \\
\hline Guam & - & 1 & - & 1 & - & - & - & - & - \\
\hline Puerto Rico & 7 & - & - & - & - & - & - & - & - \\
\hline U.S. Virgin Islands & - & - & - & - & - & - & - & - & - \\
\hline
\end{tabular}

N: Not Reportable U: Unavailable —: No reported cases C.N.M.I.: Commonwealth of Northern Mariana Islands

* No cases of anthrax; dengue hemorrhagic fever; diphtheria; eastern equine encephalitis virus disease, nonneuroinvasive; poliomyelitis, paralytic; poliovirus infection, nonparalytic; severe acute respiratory syndrome-associated coronavirus disease (SARS-CoV); smallpox; western equine encephalitis virus disease, neuroinvasive and nonneuroinvasive; yellow fever; and viral hemorrhagic fevers were reported in the United States during 2015. 
TABLE 2k. Reported cases of notifiable diseases, ${ }^{*}$ by geographic division and area — United States and U.S. territories, 2015

\begin{tabular}{|c|c|c|c|c|c|c|c|c|}
\hline \multirow[b]{2}{*}{ Area } & \multirow[b]{2}{*}{ Mumps } & \multirow{2}{*}{$\begin{array}{c}\text { Novel influenza A } \\
\text { virus infections }{ }^{\dagger}\end{array}$} & \multirow[b]{2}{*}{ Pertussis } & \multirow[b]{2}{*}{ Plague } & \multirow[b]{2}{*}{ Psittacosis } & \multicolumn{3}{|c|}{ Q fever } \\
\hline & & & & & & Total & Acute & Chronic \\
\hline United States & 1,329 & 7 & 20,762 & 16 & 4 & 156 & 122 & 34 \\
\hline $\begin{array}{l}\text { New England } \\
\text { Connecticut }\end{array}$ & $\begin{array}{r}16 \\
4\end{array}$ & $=$ & $\begin{array}{r}723 \\
74\end{array}$ & - & $\bar{N}$ & - & - & - \\
\hline Maine & $\stackrel{4}{-}$ & $=$ & $\begin{array}{r}14 \\
281\end{array}$ & - & N & - & - & - \\
\hline Massachusetts & 6 & - & 251 & - & - & - & - & - \\
\hline New Hampshire & 2 & - & 41 & - & - & $\mathrm{N}$ & $\mathrm{N}$ & $\mathrm{N}$ \\
\hline Rhode Island & 3 & - & 27 & - & - & - & - & - \\
\hline Vermont & 1 & - & 49 & - & - & $\mathrm{N}$ & - & - \\
\hline Mid. Atlantic & 166 & 1 & 2,431 & - & 1 & 14 & 11 & 3 \\
\hline New Jersey & 27 & 1 & 491 & - & 1 & 3 & 3 & - \\
\hline New York(Upstate) & 24 & - & 616 & - & - & 4 & 3 & 1 \\
\hline New York City & 101 & - & 436 & - & - & - & - & - \\
\hline Pennsylvania & 14 & - & 888 & - & - & 7 & 5 & 2 \\
\hline E. N. Central & 528 & 2 & 2,998 & 1 & - & 18 & 16 & 2 \\
\hline Illinois & 430 & - & 718 & - & - & 4 & 4 & - \\
\hline Indiana & 6 & - & 223 & - & - & 1 & 1 & - \\
\hline Michigan & 8 & 1 & 475 & 1 & - & 4 & 2 & 2 \\
\hline Ohio & 18 & 1 & 827 & - & - & 4 & 4 & - \\
\hline Wisconsin & 66 & - & 755 & - & - & 5 & 5 & - \\
\hline W.N. Central & 451 & 4 & 2,033 & - & 2 & 19 & 15 & 4 \\
\hline lowa & 411 & 1 & 173 & - & - & $\mathrm{N}$ & $\mathrm{N}$ & $\mathrm{N}$ \\
\hline Kansas & - & - & 421 & - & - & - & - & - \\
\hline Minnesota & 6 & 3 & 598 & - & - & 2 & 2 & - \\
\hline Missouri & 32 & - & 266 & - & - & 7 & 5 & 2 \\
\hline Nebraska & 2 & - & 515 & - & 2 & 5 & 3 & 2 \\
\hline North Dakota & - & - & 43 & - & - & - & - & - \\
\hline South Dakota & - & - & 17 & - & - & 5 & 5 & - \\
\hline S. Atlantic & 67 & - & 1,811 & 1 & 1 & 16 & 12 & 4 \\
\hline Delaware & 2 & - & 20 & - & - & 1 & 1 & - \\
\hline District of Columbia & - & - & 11 & - & - & $\mathrm{N}$ & - & - \\
\hline Florida & 10 & - & 339 & - & 1 & 1 & 1 & - \\
\hline Georgia & - & - & 244 & 1 & - & 3 & - & 3 \\
\hline Maryland & 16 & - & 134 & - & - & 2 & 2 & - \\
\hline North Carolina & 4 & - & 443 & - & - & 4 & 4 & - \\
\hline South Carolina & - & - & 171 & - & - & 3 & 3 & - \\
\hline Virginia & 34 & - & 369 & - & - & - & - & - \\
\hline West Virginia & 1 & - & 80 & - & - & 2 & 1 & 1 \\
\hline E.S. Central & 8 & - & 542 & - & - & 4 & 4 & - \\
\hline Alabama & 1 & - & 160 & - & - & - & - & - \\
\hline Kentucky & 4 & - & 184 & - & - & - & - & - \\
\hline Mississippi & - & - & 12 & - & - & 1 & 1 & - \\
\hline Tennessee & 3 & - & 186 & - & - & 3 & 3 & - \\
\hline W.S. Central & 30 & - & 1,706 & - & - & 17 & 11 & 6 \\
\hline Arkansas & 7 & - & 59 & - & - & 3 & 3 & $\mathrm{~N}$ \\
\hline Louisiana & 2 & - & 55 & - & - & - & - & - \\
\hline Oklahoma & 1 & - & 88 & - & - & 1 & - & 1 \\
\hline Texas & 20 & - & 1,504 & - & $N$ & 13 & 8 & 5 \\
\hline Mountain & 17 & - & 2,798 & 11 & - & 24 & 16 & 8 \\
\hline Arizona & 2 & - & 580 & 2 & - & 7 & 4 & 3 \\
\hline Colorado & 6 & - & 913 & 4 & - & 8 & 7 & 1 \\
\hline Idaho & 8 & - & 194 & - & - & 1 & - & 1 \\
\hline Montana & - & - & 230 & - & - & 5 & 3 & 2 \\
\hline Nevada & - & - & 112 & - & - & 3 & 2 & 1 \\
\hline New Mexico & 1 & - & 242 & 4 & - & - & - & - \\
\hline Utah & - & - & 498 & 1 & - & - & - & - \\
\hline Wyoming & - & - & 29 & - & - & - & - & - \\
\hline Pacific & 46 & - & 5,720 & 3 & - & 44 & 37 & 7 \\
\hline Alaska & - & - & 105 & - & - & - & - & - \\
\hline California & 33 & - & 3,597 & 1 & - & 39 & 33 & 6 \\
\hline Hawaii & 3 & - & 47 & - & - & - & - & - \\
\hline Oregon & 3 & - & 589 & 2 & - & 2 & 2 & - \\
\hline Washington & 7 & - & 1,382 & - & - & 3 & 2 & 1 \\
\hline \multicolumn{9}{|l|}{ Territories } \\
\hline American Samoa & - & - & - & - & $\mathrm{N}$ & $\mathrm{N}$ & $\mathrm{N}$ & $\mathrm{N}$ \\
\hline C.N.M.I. & - & - & - & - & - & - & - & - \\
\hline Guam & 5 & - & 55 & - & - & $\mathrm{N}$ & $\mathrm{N}$ & $\mathrm{N}$ \\
\hline Puerto Rico & 4 & - & 10 & - & $\mathrm{N}$ & - & - & - \\
\hline U.S. Virgin Islands & - & - & - & - & - & - & - & - \\
\hline
\end{tabular}

N: Not Reportable U: Unavailable -: No reported cases C.N.M.I.: Commonwealth of Northern Mariana Islands

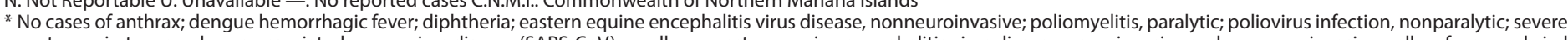

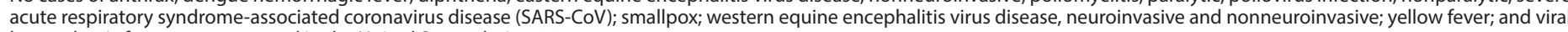
hemorrhagic fevers were reported in the United States during 2015.

† Totals reported to the Influenza Division (ID), National Center for Immunization and Respiratory Diseases (NCIRD), as of June 30, 2016. 
TABLE 2I. Reported cases of notifiable diseases, ${ }^{*}$ by geographic division and area — United States and U.S. territories, 2015

\begin{tabular}{|c|c|c|c|c|c|c|c|}
\hline Area & Rabies animal $^{\dagger}$ & Rabies human & Rubella & $\begin{array}{c}\text { Rubella, } \\
\text { congenital } \\
\text { syndrome }\end{array}$ & Salmonellosis & $\begin{array}{c}\text { Shiga toxin- } \\
\text { producing } \\
\text { Escherichia Coli } \\
\text { (STEC) } \\
\end{array}$ & Shigellosis \\
\hline United States & 5,491 & 2 & 5 & 1 & 55,108 & 7,059 & 23,590 \\
\hline $\begin{array}{l}\text { New England } \\
\text { Connecticut } \\
\text { Maine } \\
\text { Massachusetts } \\
\text { New Hampshire } \\
\text { Rhode Island } \\
\text { Vermont }\end{array}$ & $\begin{array}{r}415 \\
170 \\
34 \\
145 \\
24 \\
17 \\
25\end{array}$ & $\begin{array}{l}1 \\
- \\
-1 \\
- \\
-\end{array}$ & $\begin{array}{l}= \\
\overline{-} \\
= \\
\overline{-}\end{array}$ & $\begin{array}{l}- \\
- \\
- \\
- \\
-\end{array}$ & $\begin{array}{r}2,103 \\
434 \\
123 \\
1,153 \\
173 \\
144 \\
76\end{array}$ & $\begin{array}{r}247 \\
82 \\
29 \\
69 \\
29 \\
9 \\
29\end{array}$ & $\begin{array}{r}265 \\
57 \\
4 \\
165 \\
5 \\
28 \\
6\end{array}$ \\
\hline $\begin{array}{l}\text { Mid. Atlantic } \\
\text { New Jersey } \\
\text { New York (Upstate) } \\
\text { New York City } \\
\text { Pennsylvania }\end{array}$ & $\begin{array}{r}1,031 \\
308 \\
372 \\
6 \\
345\end{array}$ & $\begin{array}{l}- \\
\overline{-} \\
-\end{array}$ & $\begin{array}{l}- \\
\overline{-} \\
-\end{array}$ & $\begin{array}{c}\frac{1}{-} \\
\frac{1}{-}\end{array}$ & $\begin{array}{r}4,975 \\
1,145 \\
1,312 \\
929 \\
1,589\end{array}$ & $\begin{array}{l}667 \\
137 \\
199 \\
104 \\
227\end{array}$ & $\begin{array}{r}1,811 \\
370 \\
335 \\
685 \\
421\end{array}$ \\
\hline $\begin{array}{l}\text { E. N. Central } \\
\text { Illinois } \\
\text { Indiana } \\
\text { Michigan } \\
\text { Ohio } \\
\text { Wisconsin }\end{array}$ & $\begin{array}{r}196 \\
97 \\
13 \\
38 \\
26 \\
22\end{array}$ & $\begin{array}{l}= \\
\overline{-} \\
\overline{-} \\
-\end{array}$ & $\begin{array}{l}\frac{1}{E} \\
= \\
- \\
1\end{array}$ & $\begin{array}{l}= \\
= \\
= \\
-\end{array}$ & $\begin{array}{r}5,806 \\
1,839 \\
667 \\
962 \\
1,359 \\
979\end{array}$ & $\begin{array}{l}927 \\
179 \\
136 \\
124 \\
262 \\
226\end{array}$ & $\begin{array}{r}2,641 \\
886 \\
278 \\
507 \\
693 \\
277\end{array}$ \\
\hline $\begin{array}{l}\text { W.N. Central } \\
\text { lowa } \\
\text { Kansas } \\
\text { Minnesota } \\
\text { Missouri } \\
\text { Nebraska } \\
\text { North Dakota } \\
\text { South Dakota }\end{array}$ & $\begin{array}{r}234 \\
12 \\
100 \\
28 \\
31 \\
28 \\
6 \\
29\end{array}$ & $\begin{array}{l}\bar{z} \\
\overline{-} \\
\overline{-} \\
\overline{-} \\
\overline{-}\end{array}$ & $\begin{array}{l}\frac{1}{-} \\
- \\
- \\
- \\
-\end{array}$ & $\begin{array}{l}= \\
= \\
= \\
= \\
=\end{array}$ & $\begin{array}{r}3,760 \\
618 \\
509 \\
970 \\
984 \\
309 \\
145 \\
225\end{array}$ & $\begin{array}{r}1,031 \\
164 \\
121 \\
268 \\
244 \\
128 \\
44 \\
62\end{array}$ & $\begin{array}{r}2,658 \\
683 \\
150 \\
299 \\
1,126 \\
92 \\
24 \\
284\end{array}$ \\
\hline $\begin{array}{l}\text { S. Atlantic } \\
\text { Delaware } \\
\text { District of Columbia } \\
\text { Florida } \\
\text { Georgia } \\
\text { Maryland } \\
\text { North Carolina } \\
\text { South Carolina } \\
\text { Virginia } \\
\text { West Virginia }\end{array}$ & $\begin{array}{r}1,764 \\
11 \\
10 \\
85 \\
266 \\
342 \\
342 \\
130 \\
528 \\
50\end{array}$ & $\begin{array}{l}\overline{-} \\
\overline{-} \\
\overline{-} \\
\overline{-} \\
\overline{-} \\
-\end{array}$ & $\begin{array}{l}1 \\
- \\
- \\
- \\
- \\
- \\
-\end{array}$ & $\begin{array}{l}- \\
= \\
= \\
= \\
= \\
=\end{array}$ & $\begin{array}{r}14,751 \\
159 \\
122 \\
5,924 \\
2,154 \\
960 \\
2,538 \\
1,514 \\
1,181 \\
199\end{array}$ & $\begin{array}{r}583 \\
5 \\
5 \\
135 \\
107 \\
85 \\
78 \\
38 \\
107 \\
23\end{array}$ & $\begin{array}{r}4,341 \\
21 \\
45 \\
1,737 \\
1,302 \\
234 \\
381 \\
287 \\
317 \\
17\end{array}$ \\
\hline $\begin{array}{l}\text { E.S. Central } \\
\text { Alabama } \\
\text { Kentucky } \\
\text { Mississippi } \\
\text { Tennessee }\end{array}$ & $\begin{array}{r}139 \\
87 \\
11 \\
4 \\
37\end{array}$ & $\begin{array}{l}- \\
z \\
-\end{array}$ & $\begin{array}{l}- \\
\overline{-} \\
-\end{array}$ & $\begin{array}{l}- \\
\overline{-} \\
=\end{array}$ & $\begin{array}{r}3,648 \\
1,151 \\
537 \\
1,066 \\
894\end{array}$ & $\begin{array}{r}302 \\
41 \\
74 \\
22 \\
165\end{array}$ & $\begin{array}{r}1,418 \\
679 \\
417 \\
100 \\
222\end{array}$ \\
\hline $\begin{array}{l}\text { W.S. Central } \\
\text { Arkansas } \\
\text { Louisiana } \\
\text { Oklahoma } \\
\text { Texas }\end{array}$ & $\begin{array}{r}1,116 \\
73 \\
5 \\
86 \\
952\end{array}$ & $\begin{array}{l}- \\
- \\
-\end{array}$ & $\begin{array}{l}\frac{2}{-} \\
\frac{-}{2}\end{array}$ & $\begin{array}{l}\overline{-} \\
\overline{-} \\
\overline{-}\end{array}$ & $\begin{array}{r}8,733 \\
773 \\
1,328 \\
905 \\
5,727\end{array}$ & $\begin{array}{r}904 \\
85 \\
45 \\
164 \\
610\end{array}$ & $\begin{array}{r}7,012 \\
115 \\
224 \\
1,050 \\
5,623\end{array}$ \\
\hline $\begin{array}{l}\text { Mountain } \\
\text { Arizona } \\
\text { Colorado } \\
\text { Idaho } \\
\text { Montana } \\
\text { Nevada } \\
\text { New Mexico } \\
\text { Utah } \\
\text { Wyoming }\end{array}$ & $\begin{array}{r}329 \\
120 \\
119 \\
10 \\
22 \\
8 \\
13 \\
22 \\
15\end{array}$ & $\begin{array}{l}1 \\
- \\
- \\
- \\
- \\
-\end{array}$ & $\begin{array}{l}\overline{-} \\
\overline{-} \\
\overline{-} \\
\overline{-} \\
=\end{array}$ & $\begin{array}{l}- \\
- \\
- \\
- \\
- \\
-\end{array}$ & $\begin{array}{r}3,843 \\
1,160 \\
618 \\
588 \\
195 \\
276 \\
447 \\
460 \\
99\end{array}$ & $\begin{array}{r}807 \\
128 \\
207 \\
157 \\
85 \\
59 \\
36 \\
97 \\
38\end{array}$ & $\begin{array}{r}871 \\
549 \\
110 \\
31 \\
14 \\
44 \\
77 \\
36 \\
10\end{array}$ \\
\hline $\begin{array}{l}\text { Pacific } \\
\text { Alaska } \\
\text { California } \\
\text { Hawaii } \\
\text { Oregon } \\
\text { Washington }\end{array}$ & $\begin{array}{r}267 \\
7 \\
230 \\
\overline{20} \\
10\end{array}$ & $\begin{array}{l}- \\
= \\
= \\
-\end{array}$ & $\begin{array}{l}= \\
\overline{-} \\
= \\
-\end{array}$ & $\begin{array}{l}- \\
= \\
= \\
-\end{array}$ & $\begin{array}{r}7,489 \\
78 \\
5,562 \\
286 \\
528 \\
1,035\end{array}$ & $\begin{array}{r}1,591 \\
10 \\
926 \\
40 \\
229 \\
386\end{array}$ & $\begin{array}{r}2,573 \\
5 \\
2,224 \\
80 \\
112 \\
152\end{array}$ \\
\hline $\begin{array}{l}\text { Territories } \\
\text { American Samoa } \\
\text { C.N.M.I. } \\
\text { Guam } \\
\text { Puerto Rico } \\
\text { U.S. Virgin Islands }\end{array}$ & $\begin{array}{l}- \\
\overline{-} \\
\frac{17}{-}\end{array}$ & $\begin{array}{l}\frac{U}{-} \\
\frac{1}{-}\end{array}$ & $\begin{array}{l}- \\
\overline{-} \\
-\end{array}$ & $\begin{array}{l}- \\
\overline{-} \\
=\end{array}$ & $\begin{array}{r}- \\
18 \\
641 \\
-\end{array}$ & $\begin{array}{l}- \\
\bar{z} \\
-\end{array}$ & $\begin{array}{l}- \\
\overline{14} \\
19 \\
-\end{array}$ \\
\hline
\end{tabular}


TABLE 2m. Reported cases of notifiable diseases,* by geographic division and area — United States and U.S. territories, 2015

\begin{tabular}{|c|c|c|c|c|c|c|c|c|c|}
\hline \multirow[b]{2}{*}{ Area } & \multicolumn{3}{|c|}{ Spotted fever rickettsiosis } & \multirow{2}{*}{$\begin{array}{l}\text { Streptococcal } \\
\text { Toxic-shock } \\
\text { syndrome }\end{array}$} & \multicolumn{2}{|c|}{$\begin{array}{l}\text { Streptococcus pneumoniae } \\
\text { invasive disease (IPD) }^{\dagger}\end{array}$} & \multicolumn{3}{|c|}{ Syphilis ${ }^{\S, \uparrow}$} \\
\hline & Total & Confirmed & Probable & & All ages & Age $<5$ years & All stages & Congenital & $\begin{array}{l}\text { Primary \& } \\
\text { secondary }\end{array}$ \\
\hline United States & 4,198 & 199 & 3,999 & 335 & 16,163 & 1,177 & 74,702 & 487 & 23,872 \\
\hline $\begin{array}{l}\text { New England } \\
\text { Connecticut } \\
\text { Maine } \\
\text { Massachusetts } \\
\text { New Hampshire } \\
\text { Rhode Island } \\
\text { Vermont }\end{array}$ & $\begin{array}{r}21 \\
5 \\
1 \\
13 \\
2 \\
\end{array}$ & $\begin{array}{r}2 \\
1 \\
-1 \\
- \\
- \\
-\end{array}$ & $\begin{array}{r}19 \\
4 \\
1 \\
12 \\
-2 \\
-\end{array}$ & $\begin{array}{r}50 \\
23 \\
13 \\
9 \\
1 \\
3 \\
1\end{array}$ & $\begin{array}{r}1,086 \\
238 \\
135 \\
487 \\
102 \\
62 \\
62\end{array}$ & $\begin{array}{r}45 \\
6 \\
5 \\
20 \\
7 \\
3 \\
4\end{array}$ & $\begin{array}{r}1,783 \\
220 \\
38 \\
1,263 \\
84 \\
163 \\
15\end{array}$ & $\begin{array}{r}5 \\
1 \\
-4 \\
- \\
-\end{array}$ & $\begin{array}{r}664 \\
92 \\
28 \\
418 \\
40 \\
77 \\
9\end{array}$ \\
\hline $\begin{array}{l}\text { Mid. Atlantic } \\
\text { New Jersey } \\
\text { New York (Upstate) } \\
\text { New York City } \\
\text { Pennsylvania }\end{array}$ & $\begin{array}{r}119 \\
63 \\
36 \\
4 \\
16\end{array}$ & $\begin{array}{r}7 \\
1 \\
6 \\
- \\
-\end{array}$ & $\begin{array}{r}112 \\
62 \\
30 \\
4 \\
16\end{array}$ & $\begin{array}{l}30 \\
15 \\
14 \\
1\end{array}$ & $\begin{array}{r}2,474 \\
538 \\
805 \\
664 \\
467\end{array}$ & $\begin{array}{r}135 \\
27 \\
41 \\
39 \\
28\end{array}$ & $\begin{array}{r}10,889 \\
1,306 \\
1,540 \\
6,255 \\
1,788\end{array}$ & $\begin{array}{l}19 \\
3 \\
9 \\
7\end{array}$ & $\begin{array}{r}3,033 \\
372 \\
502 \\
1,504 \\
655\end{array}$ \\
\hline $\begin{array}{l}\text { E. N. Central } \\
\text { Illinois } \\
\text { Indiana } \\
\text { Michigan } \\
\text { Ohio } \\
\text { Wisconsin }\end{array}$ & $\begin{array}{r}101 \\
52 \\
30 \\
2 \\
12 \\
5\end{array}$ & $\begin{array}{r}2 \\
1 \\
- \\
-1 \\
-\end{array}$ & $\begin{array}{r}99 \\
51 \\
30 \\
2 \\
11 \\
5\end{array}$ & $\begin{array}{r}111 \\
70 \\
21 \\
11 \\
7 \\
2\end{array}$ & $\begin{array}{r}2,822 \\
N \\
627 \\
779 \\
978 \\
438\end{array}$ & $\begin{array}{r}171 \\
3 \\
38 \\
43 \\
57 \\
30\end{array}$ & $\begin{array}{r}6,687 \\
3,289 \\
699 \\
1,089 \\
1,348 \\
262\end{array}$ & $\begin{array}{r}63 \\
30 \\
5 \\
11 \\
17 \\
-\end{array}$ & $\begin{array}{r}2,412 \\
1,085 \\
285 \\
403 \\
560 \\
79\end{array}$ \\
\hline $\begin{array}{l}\text { W.N. Central } \\
\text { lowa } \\
\text { Kansas } \\
\text { Minnesota } \\
\text { Missouri } \\
\text { Nebraska } \\
\text { North Dakota } \\
\text { South Dakota }\end{array}$ & $\begin{array}{r}521 \\
8 \\
146 \\
10 \\
324 \\
25 \\
6 \\
2\end{array}$ & $\begin{array}{l}\frac{10}{1} \\
- \\
4 \\
-1 \\
-1\end{array}$ & $\begin{array}{r}511 \\
8 \\
145 \\
10 \\
320 \\
21 \\
6 \\
1\end{array}$ & $\begin{array}{r}16 \\
- \\
10 \\
2 \\
1 \\
-3\end{array}$ & $\begin{array}{r}1,035 \\
\mathrm{~N} \\
173 \\
530 \\
\mathrm{~N} \\
141 \\
82 \\
109\end{array}$ & $\begin{array}{r}83 \\
N \\
13 \\
36 \\
20 \\
8 \\
6 \\
N\end{array}$ & $\begin{array}{r}2,096 \\
232 \\
240 \\
653 \\
777 \\
81 \\
42 \\
71\end{array}$ & $\begin{array}{l}5 \\
- \\
2 \\
3 \\
- \\
-\end{array}$ & $\begin{array}{r}810 \\
75 \\
87 \\
246 \\
307 \\
45 \\
11 \\
39\end{array}$ \\
\hline $\begin{array}{l}\text { S. Atlantic } \\
\text { Delaware } \\
\text { District of Columbia } \\
\text { Florida } \\
\text { Georgia } \\
\text { Maryland } \\
\text { North Carolina } \\
\text { South Carolina } \\
\text { Virginia } \\
\text { West Virginia }\end{array}$ & $\begin{array}{r}969 \\
19 \\
-21 \\
21 \\
114 \\
4 \\
459 \\
47 \\
296 \\
9\end{array}$ & $\begin{array}{r}126 \\
- \\
- \\
114 \\
- \\
5 \\
2 \\
5 \\
-\end{array}$ & $\begin{array}{r}843 \\
19 \\
-21 \\
- \\
4 \\
454 \\
45 \\
291 \\
9\end{array}$ & $\begin{array}{r}54 \\
- \\
N \\
20 \\
- \\
10 \\
4 \\
19 \\
1\end{array}$ & $\begin{array}{r}2,673 \\
77 \\
67 \\
431 \\
991 \\
411 \\
\mathrm{~N} \\
439 \\
28 \\
229\end{array}$ & $\begin{array}{r}242 \\
6 \\
6 \\
68 \\
76 \\
22 \\
\mathrm{~N} \\
21 \\
28 \\
15\end{array}$ & $\begin{array}{r}18,297 \\
110 \\
322 \\
7,132 \\
4,156 \\
1,870 \\
2,741 \\
834 \\
1,023 \\
109\end{array}$ & $\begin{array}{r}94 \\
1 \\
1 \\
38 \\
21 \\
18 \\
9 \\
3 \\
3 \\
-\end{array}$ & $\begin{array}{r}6,017 \\
41 \\
95 \\
2,083 \\
1,413 \\
509 \\
1,196 \\
294 \\
334 \\
52\end{array}$ \\
\hline $\begin{array}{l}\text { E.S. Central } \\
\text { Alabama } \\
\text { Kentucky } \\
\text { Mississippi } \\
\text { Tennessee }\end{array}$ & $\begin{array}{r}1,127 \\
288 \\
134 \\
100 \\
605\end{array}$ & $\begin{array}{r}20 \\
1 \\
- \\
4 \\
15\end{array}$ & $\begin{array}{r}1,107 \\
287 \\
134 \\
96 \\
590\end{array}$ & $\begin{array}{r}5 \\
\mathrm{~N} \\
5 \\
\mathrm{~N} \\
-\end{array}$ & $\begin{array}{r}1,628 \\
298 \\
219 \\
246 \\
865\end{array}$ & $\begin{array}{r}123 \\
28 \\
10 \\
27 \\
58\end{array}$ & $\begin{array}{r}3,091 \\
657 \\
433 \\
760 \\
1,241\end{array}$ & $\begin{array}{r}9 \\
3 \\
1 \\
-5\end{array}$ & $\begin{array}{l}993 \\
280 \\
145 \\
219 \\
349\end{array}$ \\
\hline $\begin{array}{l}\text { W.S. Central } \\
\text { Arkansas } \\
\text { Louisiana } \\
\text { Oklahoma } \\
\text { Texas }\end{array}$ & $\begin{array}{r}1,272 \\
889 \\
15 \\
307 \\
61\end{array}$ & $\begin{array}{r}15 \\
5 \\
1 \\
7 \\
2\end{array}$ & $\begin{array}{r}1,257 \\
884 \\
14 \\
300 \\
59\end{array}$ & $\begin{array}{l}3 \\
3 \\
N \\
N\end{array}$ & $\begin{array}{r}2,371 \\
324 \\
354 \\
\mathrm{~N} \\
1,693\end{array}$ & $\begin{array}{r}234 \\
25 \\
30 \\
19 \\
160\end{array}$ & $\begin{array}{r}11,733 \\
500 \\
2,465 \\
521 \\
8,247\end{array}$ & $\begin{array}{r}114 \\
5 \\
53 \\
7 \\
49\end{array}$ & $\begin{array}{r}2,719 \\
134 \\
696 \\
209 \\
1,680\end{array}$ \\
\hline $\begin{array}{l}\text { Mountain } \\
\text { Arizona } \\
\text { Colorado } \\
\text { Idaho } \\
\text { Montana } \\
\text { Nevada } \\
\text { New Mexico } \\
\text { Utah } \\
\text { Wyoming }\end{array}$ & $\begin{array}{r}48 \\
17 \\
7 \\
3 \\
9 \\
2 \\
2 \\
7 \\
1\end{array}$ & $\begin{array}{l}17 \\
10 \\
- \\
5 \\
1 \\
-1 \\
-\end{array}$ & $\begin{array}{r}31 \\
7 \\
7 \\
3 \\
4 \\
1 \\
2 \\
6 \\
1\end{array}$ & $\begin{array}{r}66 \\
1 \\
14 \\
5 \\
4 \\
18 \\
23 \\
1\end{array}$ & $\begin{array}{r}1,909 \\
678 \\
505 \\
\mathrm{~N} \\
60 \\
174 \\
284 \\
189 \\
19\end{array}$ & $\begin{array}{r}133 \\
49 \\
29 \\
11 \\
11 \\
18 \\
14 \\
1\end{array}$ & $\begin{array}{r}3,597 \\
1,496 \\
553 \\
102 \\
20 \\
915 \\
332 \\
169 \\
10\end{array}$ & $\begin{array}{l}24 \\
14 \\
- \\
- \\
- \\
2 \\
- \\
-\end{array}$ & $\begin{array}{r}1,427 \\
589 \\
245 \\
57 \\
13 \\
335 \\
118 \\
65 \\
5\end{array}$ \\
\hline $\begin{array}{l}\text { Pacific } \\
\text { Alaska } \\
\text { California } \\
\text { Hawaii } \\
\text { Oregon } \\
\text { Washington } \\
\end{array}$ & $\begin{array}{r}20 \\
\mathrm{~N} \\
10 \\
\mathrm{~N} \\
6 \\
4\end{array}$ & $\begin{array}{l}\bar{N} \\
\bar{N} \\
- \\
-\end{array}$ & $\begin{array}{r}20 \\
\mathrm{~N} \\
10 \\
\mathrm{~N} \\
6 \\
4 \\
\end{array}$ & $\begin{array}{l}\bar{N} \\
\mathrm{~N} \\
\bar{N}\end{array}$ & $\begin{array}{r}165 \\
99 \\
\mathrm{~N} \\
66 \\
\mathrm{~N} \\
\mathrm{~N}\end{array}$ & $\begin{array}{r}11 \\
7 \\
\mathrm{~N} \\
4 \\
\mathrm{~N} \\
\mathrm{~N}\end{array}$ & $\begin{array}{r}16,529 \\
24 \\
14,450 \\
163 \\
783 \\
1,109 \\
\end{array}$ & $\begin{array}{r}154 \\
141 \\
2 \\
6 \\
5\end{array}$ & $\begin{array}{r}5,797 \\
8 \\
4,908 \\
91 \\
345 \\
445 \\
\end{array}$ \\
\hline $\begin{array}{l}\text { Territories } \\
\text { American Samoa } \\
\text { C.N.M.I. } \\
\text { Guam } \\
\text { Puerto Rico } \\
\text { U.S. Virgin Islands }\end{array}$ & $\begin{array}{l}\mathrm{N} \\
\mathrm{N} \\
\mathrm{N} \\
-\end{array}$ & $\begin{array}{l}\mathrm{N} \\
\mathrm{N} \\
\mathrm{N} \\
-\end{array}$ & $\begin{array}{l}\mathrm{N} \\
\mathrm{N} \\
\mathrm{N} \\
-\end{array}$ & $\begin{array}{l}\mathrm{N} \\
- \\
\mathrm{N} \\
-\end{array}$ & $\begin{array}{l}\mathrm{N} \\
- \\
- \\
-\end{array}$ & $\begin{array}{l}- \\
- \\
-\end{array}$ & $\begin{array}{r}- \\
21 \\
1,267 \\
25\end{array}$ & $\begin{array}{l}- \\
-1 \\
5 \\
-\end{array}$ & $\begin{array}{r}- \\
- \\
531 \\
8\end{array}$ \\
\hline
\end{tabular}

N: Not Reportable U: Unavailable —: No reported cases C.N.M.I.: Commonwealth of Northern Mariana Islands

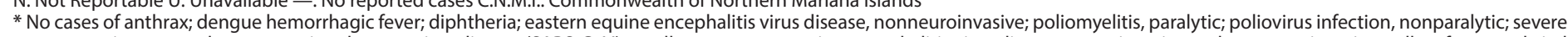

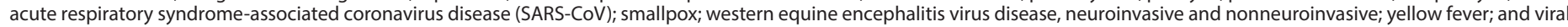
hemorrhagic fevers were reported in the United States during 2015.

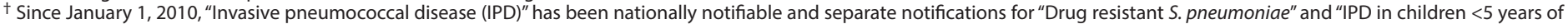
age" have been discontinued.

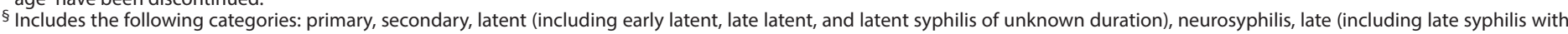
clinical manifestations other than neurosyphilis), and congenital syphilis.

" Totals reported to the Division of STD Prevention (DSTDP), National Center for HIV/AIDS, Viral Hepatitis, STD, and TB Prevention (NCHHSTP), as of June 8, 2016. 
TABLE 2n. Reported cases of notifiable diseases, ${ }^{*}$ by geographic division and area — United States and U.S. territories, 2015

\begin{tabular}{|c|c|c|c|c|c|c|}
\hline Area & Tetanus & Toxic-shock syndrome & Trichinellosis & Tuberculosis $^{\dagger}$ & Tularemia & Typhoid fever \\
\hline United States & 29 & 64 & 14 & 9,557 & 314 & 367 \\
\hline New England & - & $-\bar{N}$ & - & 330 & 5 & 23 \\
\hline Connecticut & - & $\mathrm{N}$ & - & 70 & - & 8 \\
\hline Maine & - & - & - & 18 & - & - \\
\hline Massachusetts & - & - & - & 192 & 4 & 14 \\
\hline New Hampshire & - & - & - & 13 & 1 & - \\
\hline Rhode Island & - & - & - & 30 & - & 1 \\
\hline Vermont & - & - & - & 7 & - & - \\
\hline Mid. Atlantic & 3 & 12 & 1 & 1,291 & 4 & 87 \\
\hline New Jersey & - & 3 & - & 326 & 1 & 22 \\
\hline New York (Upstate) & 1 & 4 & - & 188 & - & 12 \\
\hline New York City & 1 & - & - & 577 & - & 40 \\
\hline Pennsylvania & 1 & 5 & 1 & 200 & 3 & 13 \\
\hline E. N. Central & 3 & 10 & 2 & 802 & 16 & 45 \\
\hline Illinois & 1 & 1 & - & 343 & 10 & 20 \\
\hline Indiana & - & 2 & 1 & 116 & 3 & 6 \\
\hline Michigan & - & 5 & - & 131 & - & 8 \\
\hline Ohio & 1 & 1 & - & 143 & 1 & 7 \\
\hline Wisconsin & 1 & 1 & 1 & 69 & 2 & 4 \\
\hline W.N. Central & 2 & 14 & - & 375 & 118 & 18 \\
\hline lowa & - & - & - & 38 & - & 7 \\
\hline Kansas & - & - & - & 36 & 34 & 1 \\
\hline Minnesota & - & 10 & - & 150 & - & 3 \\
\hline Missouri & 1 & 1 & - & 92 & 29 & 3 \\
\hline Nebraska & - & 3 & - & 33 & 25 & 1 \\
\hline North Dakota & - & - & - & 9 & 5 & 2 \\
\hline South Dakota & 1 & - & - & 17 & 25 & 1 \\
\hline S. Atlantic & 8 & 4 & 2 & 1,682 & 6 & 41 \\
\hline Delaware & - & 1 & - & 22 & - & - \\
\hline District of Columbia & - & - & - & 33 & - & - \\
\hline $\begin{array}{l}\text { Florida } \\
\text { a dis }\end{array}$ & 4 & $\mathrm{~N}$ & - & 602 & - & 6 \\
\hline Georgia & - & - & $\mathrm{N}$ & 324 & - & 4 \\
\hline Maryland & - & $\mathrm{N}$ & 2 & 176 & - & 9 \\
\hline North Carolina & 3 & 2 & - & 199 & 1 & 11 \\
\hline South Carolina & 1 & 1 & - & 104 & - & - \\
\hline Virginia & - & $\mathrm{N}$ & - & 212 & 4 & 11 \\
\hline West Virginia & - & - & - & 10 & 1 & - \\
\hline E.S. Central & 1 & 6 & - & 391 & 4 & 4 \\
\hline Alabama & 1 & $\mathrm{~N}$ & - & 119 & - & - \\
\hline Kentucky & - & - & - & 67 & 1 & 3 \\
\hline Mississippi & - & $\mathrm{N}$ & - & 74 & - & - \\
\hline Tennessee & - & 6 & - & 131 & 3 & 1 \\
\hline W.S. Central & 3 & 2 & 4 & 1,610 & 48 & 66 \\
\hline Arkansas & - & 1 & $\mathrm{~N}$ & 90 & 24 & 2 \\
\hline Louisiana & 1 & 1 & - & 119 & - & 3 \\
\hline Oklahoma & - & $\mathrm{N}$ & - & 67 & 23 & 37 \\
\hline Texas & 2 & $\mathrm{~N}$ & 4 & 1,334 & 1 & 24 \\
\hline Mountain & 5 & 8 & 4 & 464 & 99 & 13 \\
\hline Arizona & 2 & - & - & 198 & 4 & 2 \\
\hline Colorado & 2 & 7 & 2 & 73 & 52 & 6 \\
\hline Idaho & - & 1 & 1 & 11 & 2 & - \\
\hline Montana & - & - & - & 9 & 7 & - \\
\hline Nevada & - & - & - & 85 & - & 3 \\
\hline New Mexico & 1 & - & - & 47 & 8 & 1 \\
\hline Utah & - & - & 1 & 37 & 5 & 1 \\
\hline Wyoming & - & - & - & 4 & 21 & - \\
\hline Pacific & 4 & 8 & 1 & 2,612 & 14 & 70 \\
\hline Alaska & - & $\mathrm{N}$ & - & 68 & 2 & - \\
\hline California & 3 & 8 & - & 2,133 & 2 & 55 \\
\hline Hawaii & - & $\mathrm{N}$ & - & 127 & - & 4 \\
\hline Oregon & 1 & $\mathrm{~N}$ & - & 76 & 6 & 1 \\
\hline Washington & - & $\mathrm{N}$ & 1 & 208 & 4 & 10 \\
\hline \multicolumn{7}{|l|}{ Territories } \\
\hline American Samoa & - & $\mathrm{N}$ & $\mathrm{N}$ & 4 & - & - \\
\hline C.N.M.I. & - & - & - & 27 & - & - \\
\hline Guam & - & - & - & 76 & - & - \\
\hline Puerto Rico & 1 & $\mathrm{~N}$ & $\mathrm{~N}$ & 52 & - & - \\
\hline U.S. Virgin Islands & - & - & - & - & - & - \\
\hline
\end{tabular}

N: Not Reportable U: Unavailable —: No reported cases C.N.M.I.: Commonwealth of Northern Mariana Islands

* No cases of anthrax; dengue hemorrhagic fever; diphtheria; eastern equine encephalitis virus disease, nonneuroinvasive; poliomyelitis, paralytic; poliovirus infection, nonparalytic; severe acute respiratory syndrome-associated coronavirus disease (SARS-CoV); smallpox; western equine encephalitis virus disease, neuroinvasive and nonneuroinvasive; yellow fever; and viral hemorrhagic fevers were reported in the United States during 2015

† Totals reported to the Division of Tuberculosis Elimination (DTBE), National Center for HIV/AIDS, Viral Hepatitis, STD, and TB Prevention (NCHHSTP), as of June 15, 2016. 
TABLE 2o. Reported cases of notifiable diseases, ${ }^{*}$ by geographic division and area - United States and U.S. territories, 2015

\begin{tabular}{|c|c|c|c|c|c|}
\hline \multirow[b]{2}{*}{ Area } & \multirow{2}{*}{$\begin{array}{c}\text { Vancomycin-intermediate } \\
\text { Staphylococcus aureus (VISA) }\end{array}$} & \multirow{2}{*}{$\begin{array}{c}\text { Vancomycin-resistant } \\
\text { Staphylococcus aureus (VRSA) }\end{array}$} & \multicolumn{2}{|c|}{ Varicella } & \multirow[b]{2}{*}{ Vibriosis } \\
\hline & & & Morbidity & Mortality $^{\dagger}$ & \\
\hline United States & 183 & 3 & 9,789 & 6 & 1,323 \\
\hline $\begin{array}{l}\text { New England } \\
\text { Connecticut } \\
\text { Maine } \\
\text { Massachusetts } \\
\text { New Hampshire } \\
\text { Rhode Island } \\
\text { Vermont }\end{array}$ & $\begin{array}{l}\frac{5}{2} \\
3 \\
N \\
- \\
-\end{array}$ & $\begin{array}{l}- \\
= \\
= \\
= \\
-\end{array}$ & $\begin{array}{r}945 \\
165 \\
233 \\
365 \\
96 \\
53 \\
33\end{array}$ & $\begin{array}{l}- \\
\overline{-} \\
= \\
- \\
-\end{array}$ & $\begin{array}{r}127 \\
32 \\
6 \\
78 \\
6 \\
3 \\
2\end{array}$ \\
\hline $\begin{array}{l}\text { Mid. Atlantic } \\
\text { New Jersey } \\
\text { New York (Upstate) } \\
\text { New York City } \\
\text { Pennsylvania }\end{array}$ & $\begin{array}{r}45 \\
4 \\
13 \\
24 \\
4\end{array}$ & $\begin{array}{l}- \\
= \\
= \\
-\end{array}$ & $\begin{array}{r}1,207 \\
466 \\
\mathrm{~N} \\
-741\end{array}$ & $\begin{array}{l}\frac{1}{1} \\
- \\
-\end{array}$ & $\begin{array}{r}117 \\
34 \\
48 \\
18 \\
17\end{array}$ \\
\hline $\begin{array}{l}\text { E. N. Central } \\
\text { Illinois } \\
\text { Indiana } \\
\text { Michigan } \\
\text { Ohio } \\
\text { Wisconsin }\end{array}$ & $\begin{array}{r}40 \\
21 \\
\mathrm{~N} \\
4 \\
41 \\
11 \\
4\end{array}$ & $\begin{array}{l}- \\
= \\
= \\
=\end{array}$ & $\begin{array}{r}1,957 \\
443 \\
173 \\
549 \\
458 \\
334\end{array}$ & $\begin{array}{l}\frac{2}{-} \\
- \\
- \\
2\end{array}$ & $\begin{array}{r}62 \\
26 \\
3 \\
10 \\
15 \\
8\end{array}$ \\
\hline $\begin{array}{l}\text { W.N. Central } \\
\text { lowa } \\
\text { Kansas } \\
\text { Minnesota } \\
\text { Missouri } \\
\text { Nebraska } \\
\text { North Dakota } \\
\text { South Dakota }\end{array}$ & $\begin{array}{l}53 \\
\mathrm{~N} \\
- \\
\overline{51} \\
- \\
- \\
2\end{array}$ & $\begin{array}{l}- \\
= \\
= \\
= \\
=\end{array}$ & $\begin{array}{r}859 \\
N \\
240 \\
361 \\
170 \\
25 \\
36 \\
27\end{array}$ & $\begin{array}{l}1 \\
- \\
- \\
- \\
-\end{array}$ & $\begin{array}{r}33 \\
\mathrm{~N} \\
5 \\
21 \\
5 \\
1 \\
1 \\
\mathrm{~N}\end{array}$ \\
\hline $\begin{array}{l}\text { S. Atlantic } \\
\text { Delaware } \\
\text { District of Columbia } \\
\text { Florida } \\
\text { Georgia } \\
\text { Maryland } \\
\text { North Carolina } \\
\text { South Carolina } \\
\text { Virginia } \\
\text { West Virginia }\end{array}$ & $\begin{array}{r}18 \\
- \\
4 \\
5 \\
3 \\
2 \\
3 \\
1 \\
-\end{array}$ & $\begin{array}{l}1 \\
1 \\
- \\
= \\
- \\
= \\
=\end{array}$ & $\begin{array}{r}1,666 \\
16 \\
28 \\
740 \\
160 \\
\mathrm{~N} \\
\mathrm{~N} \\
208 \\
354 \\
160\end{array}$ & $\begin{array}{l}- \\
\overline{-} \\
\overline{-} \\
\overline{-} \\
= \\
=\end{array}$ & $\begin{array}{r}345 \\
11 \\
-196 \\
23 \\
37 \\
25 \\
11 \\
40 \\
2\end{array}$ \\
\hline $\begin{array}{l}\text { E.S. Central } \\
\text { Alabama } \\
\text { Kentucky } \\
\text { Mississippi } \\
\text { Tennessee }\end{array}$ & $\begin{array}{l}5 \\
2 \\
N \\
1 \\
2\end{array}$ & $\begin{array}{l}\overline{-} \\
\bar{N} \\
-\end{array}$ & $\begin{array}{r}178 \\
165 \\
\mathrm{~N} \\
13 \\
\mathrm{~N}\end{array}$ & $\begin{array}{l}\frac{1}{-} \\
- \\
1\end{array}$ & $\begin{array}{r}42 \\
18 \\
5 \\
14 \\
5\end{array}$ \\
\hline $\begin{array}{l}\text { W.S. Central } \\
\text { Arkansas } \\
\text { Louisiana } \\
\text { Oklahoma } \\
\text { Texas }\end{array}$ & $\begin{array}{r}\frac{16}{4} \\
3 \\
9\end{array}$ & $\begin{array}{r}\frac{2}{1} \\
1 \\
-\end{array}$ & $\begin{array}{r}1,799 \\
198 \\
110 \\
\mathrm{~N} \\
1,491\end{array}$ & $\begin{array}{l}- \\
\overline{-} \\
\overline{-}\end{array}$ & $\begin{array}{r}166 \\
3 \\
56 \\
5 \\
102\end{array}$ \\
\hline $\begin{array}{l}\text { Mountain } \\
\text { Arizona } \\
\text { Colorado } \\
\text { Idaho } \\
\text { Montana } \\
\text { Nevada } \\
\text { New Mexico } \\
\text { Utah } \\
\text { Wyoming }\end{array}$ & $\begin{array}{l}1 \\
1 \\
N \\
N \\
- \\
\\
\\
-\end{array}$ & $\begin{array}{l}- \\
\overline{-} \\
\bar{N} \\
\bar{N} \\
- \\
-\end{array}$ & $\begin{array}{r}1,001 \\
270 \\
311 \\
\mathrm{~N} \\
132 \\
\mathrm{~N} \\
57 \\
217 \\
14\end{array}$ & $\begin{array}{l}- \\
\overline{-} \\
= \\
= \\
= \\
=\end{array}$ & $\begin{array}{l}57 \\
33 \\
12 \\
\mathrm{~N} \\
3 \\
- \\
\\
-\end{array}$ \\
\hline $\begin{array}{l}\text { Pacific } \\
\text { Alaska } \\
\text { California } \\
\text { Hawaii } \\
\text { Oregon } \\
\text { Washington }\end{array}$ & $\begin{array}{l}\bar{N} \\
N \\
\bar{N} \\
N\end{array}$ & $\begin{array}{l}\frac{-}{N} \\
\frac{N}{N} \\
-\end{array}$ & $\begin{array}{r}177 \\
59 \\
61 \\
57 \\
N \\
N\end{array}$ & $\begin{array}{l}1 \\
-1 \\
- \\
-\end{array}$ & $\begin{array}{r}374 \\
3 \\
240 \\
37 \\
26 \\
68\end{array}$ \\
\hline $\begin{array}{l}\text { Territories } \\
\text { American Samoa } \\
\text { C.N.M.I. } \\
\text { Guam } \\
\text { Puerto Rico } \\
\text { U.S. Virgin Islands }\end{array}$ & $\begin{array}{l}\mathrm{N} \\
- \\
- \\
-\end{array}$ & $\begin{array}{l}\mathrm{N} \\
- \\
- \\
-\end{array}$ & $\begin{array}{r}\mathrm{N} \\
29 \\
103 \\
-\end{array}$ & $\begin{array}{l}- \\
\overline{-} \\
\overline{-}\end{array}$ & $\begin{array}{l}\mathrm{N} \\
- \\
- \\
-\end{array}$ \\
\hline
\end{tabular}

N: Not Reportable U: Unavailable -: No reported cases C.N.M.I.: Commonwealth of Northern Mariana Islands

* No cases of anthrax; dengue hemorrhagic fever; diphtheria; eastern equine encephalitis virus disease, nonneuroinvasive; poliomyelitis, paralytic; poliovirus infection, nonparalytic; severe

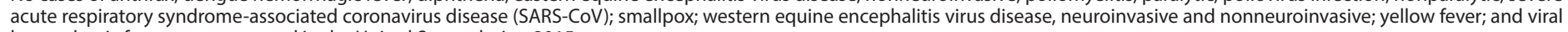
hemorrhagic fevers were reported in the United States during 2015.

† Totals reported to the Division of Viral Diseases (DVD), National Center for Immunization and Respiratory Diseases (NCIRD), as of May 2, 2016. 